\title{
Microarray and cDNA sequence analysis of transcription during
} nerve-dependent limb regeneration

\author{
James R Monaghan ${ }^{1}$, Leonard G Epp ${ }^{2}$, Srikrishna Putta1 ${ }^{1}$, Robert B Page ${ }^{1}$, \\ John A Walker ${ }^{1}$, Chris K Beachy ${ }^{3}$, Wei Zhu ${ }^{4}$, Gerald M Pao ${ }^{4}$, Inder M Verma ${ }^{4}$, \\ Tony Hunter ${ }^{4}$, Susan V Bryant ${ }^{5,6}$, David M Gardiner ${ }^{5,6}$, Tim T Harkins ${ }^{7}$ and S \\ Randal Voss*1
}

\begin{abstract}
Address: ${ }^{1}$ Department of Biology and Spinal Cord and Brain Injury Research Center, University of Kentucky, Lexington, KY 40506, USA, ${ }^{2}$ Department of Biology, Mount Union College, Alliance, OH 44601, USA, ${ }^{3}$ Department of Biology, Minot State University, Minot, SD, USA, ${ }^{4}$ The Salk Institute for Biological Studies, La Jolla, CA 92037, USA, 5epartment of Developmental and Cell Biology, University of California Irvine, Irvine, CA 92697, USA, ${ }^{6}$ The Developmental Biology Center, University of California Irvine, Irvine, CA 92697, USA and ${ }^{7}$ Roche Applied Science, Indianapolis, IN 46250, USA

Email: James R Monaghan - james.monaghan@uky.edu; Leonard G Epp - epplg@muc.edu; Srikrishna Putta - sputt2@email.uky.edu; Robert B Page - rbp0554@gmail.com; John A Walker - jawalk2@uky.edu; Chris K Beachy - christopher.beachy@minotstateu.edu; Wei Zhu - wzhu@salk.edu; Gerald M Pao - pao@salk.edu; Inder M Verma - verma@salk.edu; Tony Hunter - hunter@salk.edu; Susan V Bryant - svbryant@uci.edu; David M Gardiner - dmgardin@uci.edu; Tim T Harkins - tim.harkins@roche.com; S

Randal Voss* - srvoss@uky.edu

* Corresponding author
\end{abstract}

Published: 13 January 2009

BMC Biology 2009, 7:I doi:10.1 186/1741-7007-7-1

This article is available from: http://www.biomedcentral.com/|74|-7007/7//

(C) 2009 Monaghan et al; licensee BioMed Central Ltd.

This is an Open Access article distributed under the terms of the Creative Commons Attribution License (http://creativecommons.org/licenses/by/2.0), which permits unrestricted use, distribution, and reproduction in any medium, provided the original work is properly cited.

\begin{abstract}
Background: Microarray analysis and 454 cDNA sequencing were used to investigate a centuries-old problem in regenerative biology: the basis of nerve-dependent limb regeneration in salamanders. Innervated (NR) and denervated (DL) forelimbs of Mexican axolotls were amputated and transcripts were sampled after 0,5 , and 14 days of regeneration.

Results: Considerable similarity was observed between NR and DL transcriptional programs at 5 and 14 days post amputation (dpa). Genes with extracellular functions that are critical to wound healing were upregulated while muscle-specific genes were downregulated. Thus, many processes that are regulated during early limb regeneration do not depend upon nerve-derived factors. The majority of the transcriptional differences between NR and DL limbs were correlated with blastema formation; cell numbers increased in NR limbs after $5 \mathrm{dpa}$ and this yielded distinct transcriptional signatures of cell proliferation in NR limbs at $14 \mathrm{dpa}$. These transcriptional signatures were not observed in DL limbs. Instead, gene expression changes within DL limbs suggest more diverse and protracted wound-healing responses. $454 \mathrm{cDNA}$ sequencing complemented the microarray analysis by providing deeper sampling of transcriptional programs and associated biological processes. Assembly of new 454 cDNA sequences with existing expressed sequence tag (EST) contigs from the Ambystoma EST database more than doubled (3935 to $94 \mathrm{II}$ ) the number of non-redundant human-A. mexicanum orthologous sequences.
\end{abstract}

Conclusion: Many new candidate gene sequences were discovered for the first time and these will greatly enable future studies of wound healing, epigenetics, genome stability, and nerve-dependent blastema formation and outgrowth using the axolotl model. 


\section{Background}

Salamanders are fascinating vertebrate organisms because they routinely regenerate complex tissues. Within only a few weeks of losing a piece of limb to a hungry predator or scalpel-wielding scientist, a salamander perfectly reforms the missing structure. In the early history of salamander regeneration research, scientists innovated elegant experimental designs to probe the anatomical basis of regeneration [1]. More recently and in parallel with the discovery of conserved regulatory genes and developmental pathways among metazoans, scientists have focused attention on candidate molecules and signaling pathways whose functions were deduced first from studies of model organisms. In particular, much research has been devoted to understanding aspects of limb regeneration associated with wound healing that recapitulate limb development; this strategy has yielded many useful insights and molecular probes [2-14]. Although it is clear that key regulatory molecules play important roles in the development of all organisms, it is not clear that a framework for understanding regeneration can be constructed using a generic and limited molecular toolkit. There is a need to go beyond candidate molecules and use unbiased approaches to characterize the molecular complexity underlying salamander regeneration.

Recent research resource development for the Mexican axolotl now allows classic regeneration experiments to be re-examined with powerful and unbiased genomic approaches. One particularly elegant experiment performed almost 200 years ago showed that salamander limb regeneration requires the presence of peripheral nerves. Todd [15] found in 1823 that limb regeneration does not occur if the sciatic nerve of the hindlimb is severed shortly before or immediately after a more distal limb amputation. Subsequent research showed that the brachial nerves entering the forelimb are required to promote limb outgrowth and patterning of a new limb $[16,17]$. Within a few days of limb amputation, cells proximal to the amputation plane dedifferentiate and accumulate to form a blastema. Blastema cells proliferate and progressively differentiate during regeneration to give rise to all mesodermal structures of a typical vertebrate limb [18]. Upon amputation, nerve fibers in the vicinity of the amputation plane extend into the blastema and play a supportive role in cell proliferation $[11,19]$. Transection of the spinal nerves that enter the limb in the axolotl leads to a decrease in cycling cells and there is resorption of distal tissues of the amputated limb. Histological and cell proliferation analyses suggest that early cellular events are similar between denervated and innervated limbs, but denervated limbs are incapable of blastema formation because they do not support significant cell proliferation and outgrowth [20-25].
Although limb regeneration is a complex developmental process, nerve dependency and other aspects of regeneration have often been conceptualized as having a simple molecular basis, involving relatively few regulatory factors. For example, Ferretti and Brockes [26] hypothesized that in the absence of nerves, Schwann cells produce an inhibitory factor that prevents blastema cell proliferation. This mechanism is supported by experimental results although the hypothetical factor has not been identified $[27,28]$. Alternative mechanisms for nerve dependency have also been proposed for several factors with growth promoting effects [29-33]. A recent study identified newt anterior gradient protein (nAG) as a blastema cell growthpromoting factor in vitro, whose over-expression was sufficient to rescue regeneration of denervated and amputated limbs in vivo [34]. Most recently, nerve-dependent expression of the transcription factor $s p 9$ has been identified as an early marker of dedifferentiation of the wound epithelium and the initiation of limb regeneration [11]. While considerable progress has been made in investigating the functions of candidate regulatory factors and signaling pathways, a broader systems-level perspective is needed to understand why multiple aspects of limb regeneration are dependent upon the presence of a nerve.

Genomic tools are now available that allow global characterization of the regeneration process in salamanders. Expressed sequence tag (EST) information has facilitated the development of an Ambystoma salamander Affymetrix microarray platform [35-38]. This platform and a highthroughput 454 cDNA sequencing approach were used in this study to compare transcript abundance among uninjured limbs, regenerating limbs, and limbs denervated at the time of amputation. The results show that innervated (NR) and denervated (DL) limbs exhibited similar (but not identical) gene expression patterns at five days post amputation (dpa) but then diverged as a blastema formed under the influence of nerves. The results are discussed within the context of previous studies of nerve dependency, highlighting specific genes and biological processes that are associated with blastema formation and outgrowth, and more generally, the Mexican axolotl's unparalleled ability to regenerate limbs.

\section{Results \\ Morphology and histology of denervated and innervated limbs}

Histological staining verified our experimental procedures for creating innervated and denervated limbs on the same individual. Previous studies found few morphological or histological differences between innervated and denervated limbs during the first few days of regeneration $[16,39,40]$. Consistent with these observations, denervated and innervated limbs at $5 \mathrm{dpa}$ (DL5 and NR5) were histologically indistinguishable (Figure 1a and 1c). Histo- 


\section{DL5}

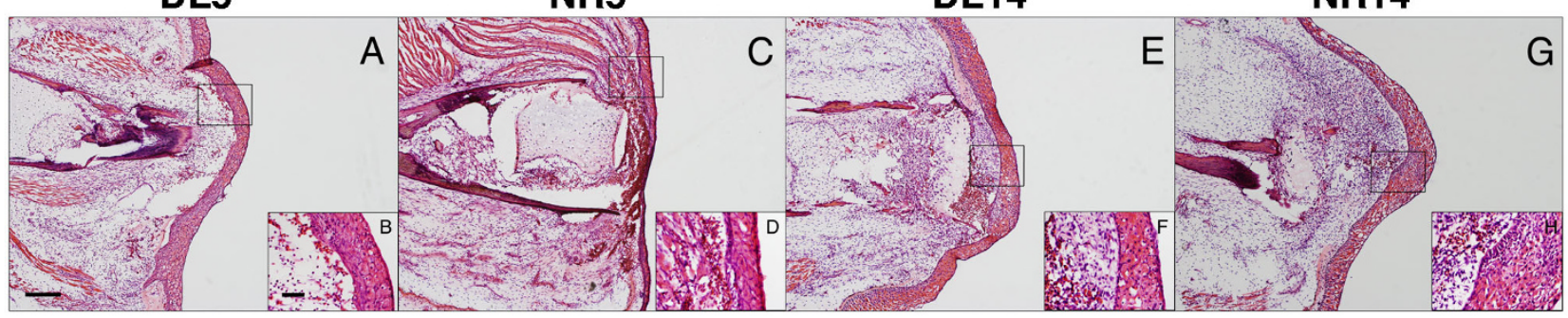

\section{Figure I}

Histology of innervated and denervated limbs at 5 and I 4 dpa. Eosin and hematoxylin staining of DL5 (A), NR5 (C), DLI4 (E), and NRI4 (G) limbs. Higher magnification inset pictures are provided for each image (B, D, F, H). Scale Bar $A=500$ $\mu \mathrm{m} ; \mathrm{B}=50 \mu \mathrm{m}$.

logical staining (hematoxylin and eosin) showed hemorrhaging directly beneath the epithelium containing Leydig cells, squamous cells, and basal keratinocytes (Figure 1b and 1d). All 5 dpa limbs resembled the wound-healing phase or early phase of dedifferentiation according to the staging of [41]. A blastema was visible on innervated limbs 14 dpa (NR14) and histological staining showed an accumulation of blastemal cells under the wound epithelium. These structures were not observed in denervated limbs at 14 dpa (DL14; Figure 1e to 1h). These results indicate that blastema formation and outgrowth only occurred in NR limbs. An apical thickening of the epithelium characterized the distal end of NR14 limbs and this layer consisted of keratinocytes and Leydig cells. These histological traits indicate that $14 \mathrm{dpa}$ limbs in this experiment corresponded to the early to mid bud stage of limb regeneration [41]. Immunological staining using RT-97 was performed to detect the presence or absence of nerve axons at 5 and $14 \mathrm{dpa}$. At both time-points, neurofilament staining was positive in the NR limbs, but negative in DL limbs. In pilot experiments, we determined that $>20$ days is required for nerves to re-innervate limbs after denervation surgery (data not shown). Thus, DL and NR limbs were created successfully and histology showed that 5 and 14 dpa time points correspond to wound-healing and early to mid bud phases of regeneration, respectively.

\section{Transcription during normal limb regeneration: Deviations of NR limbs from baseline}

At both 5 and 14 dpa, mRNA levels for hundreds of genes were significantly different from baseline levels of genes expressed in whole limbs at Day 0 (Table 1). Many of the same genes $(n=215$; up $=111$; down $=104)$ were identified as significant in NR5 and NR14 limbs; the deviation from baseline was in the same direction for all but one of these genes $(f a b p 2)$. Four matrix metalloproteinases (mmp1, mmp3/10a, mmp9, and mmp13) that are known to function during wound healing in many organisms were upregulated at both 5 and 14 dpa (Figure 2; Additional file 1), while collagens (col4a1, col4a2, colsa1, col9a3, and col11a1; Figure 3) and muscle-specific genes (Figure 4) were downregulated (Table 1; Additional file 2). Upregulation of collagen catabolism genes coupled with downregulation of collagen structural genes suggests that transcriptional activation and repression are integrated to efficiently remodel the extracellular environment of damaged tissues. Downregulation of muscle genes at both time points suggests that the differentiated muscle gene expression phenotype changes by $5 \mathrm{dpa}$, and changes more dramatically by 14 dpa.

Although many genes exhibited similar deviations from baseline at 5 and $14 \mathrm{dpa}$, unique gene expression changes were identified at each time point (Table 1; Additional files 1 and 2). The unique NR5 genes were associated with gene ontology (GO) terms that implicate extracellular protein changes and signal transduction pathways of the early wounding response. These terms included response to stimulus, signal transduction, extracellular region, and ion transport. The unique NR14 genes were associated with GO terms that implicate cell division and DNA metabolism including cond2, ccnb1, rrm1, rrm2, nasp, $\operatorname{rrc1}$, and cdc20. The unique gene expression changes that were identified at 5 and 14 dpa support the idea of temporal progression from an early wound-healing phase to a blastema outgrowth phase during normal limb regeneration.

\section{Transcription within denervated limbs: Deviations of $D L$ limbs from baseline}

As was observed in NR limbs, hundreds of genes were identified as significant when comparing DL5 and DL14 mRNA levels with baseline levels measured at Day 0 (Table 1; Additional files 1 and 2). Some of the same or similar GO terms that were associated with NR limbs were identified as significantly enriched in DL limbs. This was 
Table I: Significant gene ontology terms for changed genes

\begin{tabular}{|c|c|}
\hline upregulated & downregulated \\
\hline NR5 and NRI4 ( $N=I I I)$ & NR5 and NRI4 $(N=104)$ \\
\hline extracellular region $(\mathrm{N}=14 ; 9.05 \mathrm{E}-07)$ & muscle contraction $(\mathrm{N}=13 ; 1.81 \mathrm{E}-10)$ \\
\hline \multirow[t]{3}{*}{ collagen catabolism ( $\mathrm{N}=5 ; 4.35 \mathrm{E}-06)$} & cytoplasm $(\mathrm{N}=5 \mathrm{I} ; 8.4 \mathrm{IE}-07)$ \\
\hline & collagen $(N=6 ; 4.05 \mathrm{E}-05)$ \\
\hline & ion transport $(\mathrm{N}=12 ; 9.44 \mathrm{E}-06)$ \\
\hline NR5 only $(N=1 \mid 0)$ & NR5 only $(N=49)$ \\
\hline extracellular region $(\mathrm{N}=15 ; 1.23 \mathrm{E}-05)$ & extrinsic to membrane $(\mathrm{N}=3 ; 6.10 \mathrm{E}-03)$ \\
\hline \multicolumn{2}{|l|}{ response to stimulus $(\mathrm{N}=17 ; 1.00 \mathrm{E}-02)$} \\
\hline \multicolumn{2}{|l|}{ signal transduction $(\mathrm{N}=2 \mathrm{I} ; 2.89 \mathrm{E}-03)$} \\
\hline \multicolumn{2}{|l|}{ lon transport $(\mathrm{N}=9 ; 2.57 \mathrm{E}-03)$} \\
\hline NRI 4 only $(N=53)$ & NRI 4 only $(N=93)$ \\
\hline \multirow[t]{2}{*}{ DNA metabolic process $(\mathrm{N}=8 ; 4.4 \mathrm{IE}-04)$} & muscle contraction $(\mathrm{N}=18 ; 5.43 \mathrm{E}-19)$ \\
\hline & calcium ion binding $(\mathrm{N}=1 \mathrm{I} ; 4.98 \mathrm{E}-04)$ \\
\hline DL5 and DLI4 $(N=170)$ & DL5 and DLI $4(N=109)$ \\
\hline extracellular region $(\mathrm{N}=23 ; 6.64 \mathrm{E}-\mathrm{I} 0)$ & muscle contraction $(\mathrm{N}=15 ; 6.62 \mathrm{E}-13)$ \\
\hline lysosome (N = II; 3.04E-08) & cytoplasm $(\mathrm{N}=53 ;$ I.46E-06) \\
\hline ion transport $(\mathrm{N}=13 ;$ I.42E-05) & mitochondrial membrane $(\mathrm{N}=12 ; 3.49 \mathrm{E}-04)$ \\
\hline \multicolumn{2}{|l|}{ hydrolase activity $(\mathrm{N}=26 ; 3.60 \mathrm{E}-05)$} \\
\hline \multirow{2}{*}{\multicolumn{2}{|c|}{ response to stress $(\mathrm{N}=21 ; 1.02 \mathrm{E}-03)$}} \\
\hline signal transduction $(\mathrm{N}=22 ; 5.40 \mathrm{E}-03)$ & \\
\hline \multicolumn{2}{|l|}{ collagen catabolism $(\mathrm{N}=5 ; 5.09 \mathrm{E}-05)$} \\
\hline DL5 only $(N=68)$ & DL5 only $(\mathrm{N}=58)$ \\
\hline extracellular region $(\mathrm{N}=9 ; 3.68 \mathrm{E}-04)$ & extrinsic to membrane $(\mathrm{N}=3 ; 4.64 \mathrm{E}-03)$ \\
\hline \multicolumn{2}{|l|}{ response to stimulus ( $\mathrm{N}=12 ; 3.70 \mathrm{E}-03)$} \\
\hline DLI 4 only $(N=69)$ & DLI4 only $(\mathrm{N}=\mathrm{III})$ \\
\hline extracellular region $(\mathrm{N}=7 ; 4.10 \mathrm{E}-03)$ & muscle contraction $(\mathrm{N}=9 ; 4.26 \mathrm{E}-05)$ \\
\hline \multirow{4}{*}{ immune response $(\mathrm{N}=5 ; 7.80 \mathrm{E}-03)$} & mitochondrion ( $\mathrm{N}=27 ; 6.7 \mathrm{IE}-07)$ \\
\hline & cytoplasmic $(\mathrm{N}=43 ; 2.58 \mathrm{E}-03)$ \\
\hline & $M$ phase $(\mathrm{N}=9 ; 1.40 \mathrm{E}-03)$ \\
\hline & glucose metabolic process $(\mathrm{N}=6 ; 2.97 \mathrm{E}-03)$ \\
\hline
\end{tabular}

Significant genes were identified by microarray analysis. Gene ontology terms are represented that were sampled more often than expected in NR5, NRI4, DL5, and DLI4 limbs. P-value is calculated by DAVID [45].

not unexpected because both DL and NR limbs undergo tissue histolysis at the limb stump and carry out an early wound-healing response (Figure 1). For example, extracellular region and MMP genes were upregulated at 5 and 14 dpa, as was seen in NR limbs (Figure 2; Additional file 1). As in NR limbs, muscle contraction (Figure 4), cytoplasmic, and collagen genes (Figure 3; col4a1, col4a2, colsa1) were downregulated in both DL5 and DL14 limbs (Additional file 2). Moreover, $83 \%$ of the genes that were iden- tified as significant in NR5 limbs were also significant (and in the same direction) in DL5 limbs. These results indicate that many transcriptional events are nerve-independent during early regeneration.

Denervated limbs are known to cease growth following limb amputation. Several groups of genes may explain this observation including the downregulation of genes associated with the $\mathrm{M}$ phase of cell division, mitochon- 


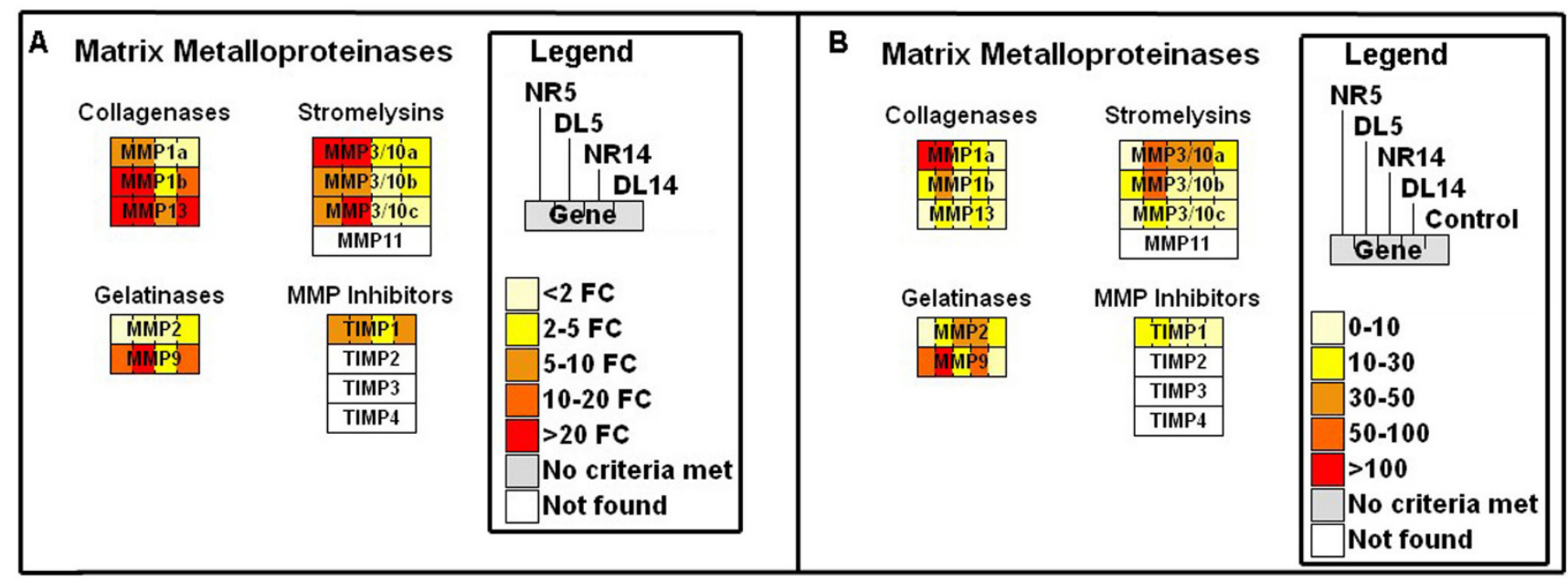

Figure 2

Schematic of matrix metalloproteinase gene expression. Matrix metalloproteinase gene expression is represented in each box. A) Microarray results are represented by fold change (FC) from day 0 . B) Normalized counts are represented from the 454 cDNA sequencing experiment. Figures 2 to 4 were created using GenMAPP [I0I]. Figure 2 was modified from a MAPP originally created by Gladstone Institutes.

drial transcripts, and genes associated with glucose metabolism (Table 1; Additional file 2). Furthermore, DL14 limbs were morphologically similar to DL5 limbs because denervation prevented blastema formation (Figure 1). Consistent with this observation, many of the genes that were identified as upregulated in DL5 limbs were also identified as significant in DL14 limbs (69\%). These genes are associated with the following GO terms: lysosome, response to stress, hydrolyse activity, signal transducer activity, and ion transport. Overall, these terms suggest protraction and expansion of wound-healing responses in
DL14 limbs, as well as changes in cellular metabolism and cell division.

\section{Transcript abundance differences between NR and $D L$ limbs}

In the preceding two sections, transcriptional patterns of NR and DL limbs were described relative to baseline levels at Day 0. Here, we report genes found to be significant when comparing NR and DL limbs. In general, few significant changes in gene expression were observed when NR5 and DL5 transcripts were compared directly. Transcripts for 16 genes were more abundant in NR5 limbs

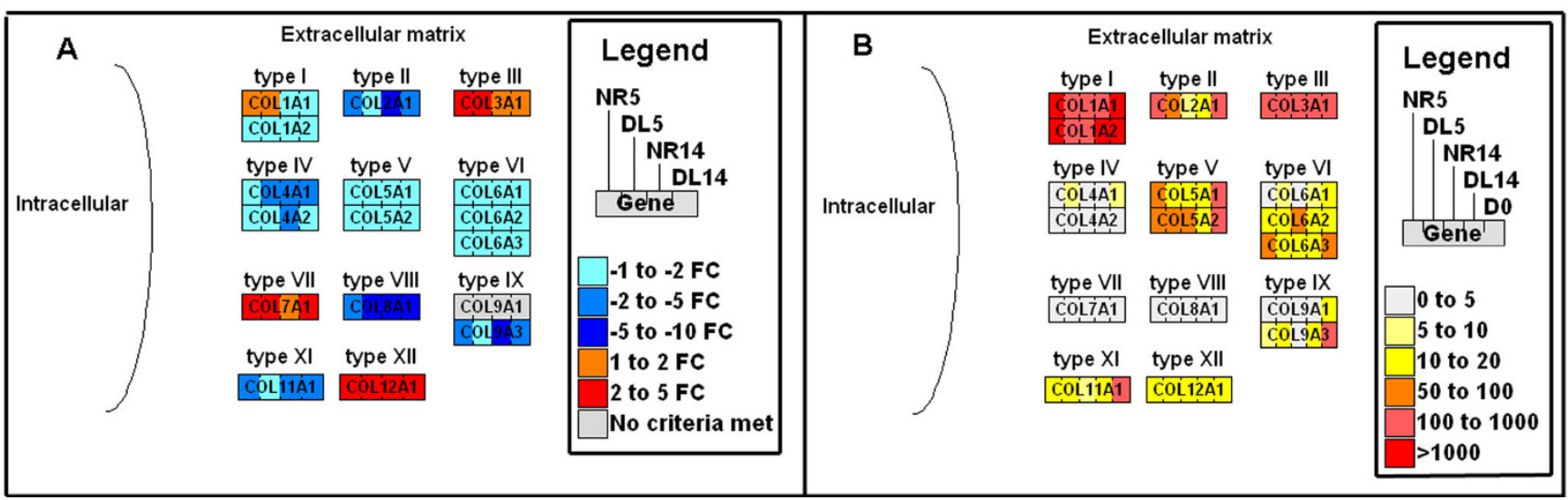

Figure 3

Schematic of collagen gene expression. Collagen gene expression is represented in each box. A) Microarray results are represented by fold change (FC) from day 0 . B) Normalized counts are represented from the 454 cDNA sequencing experiment. 
Striated Muscle Contraction

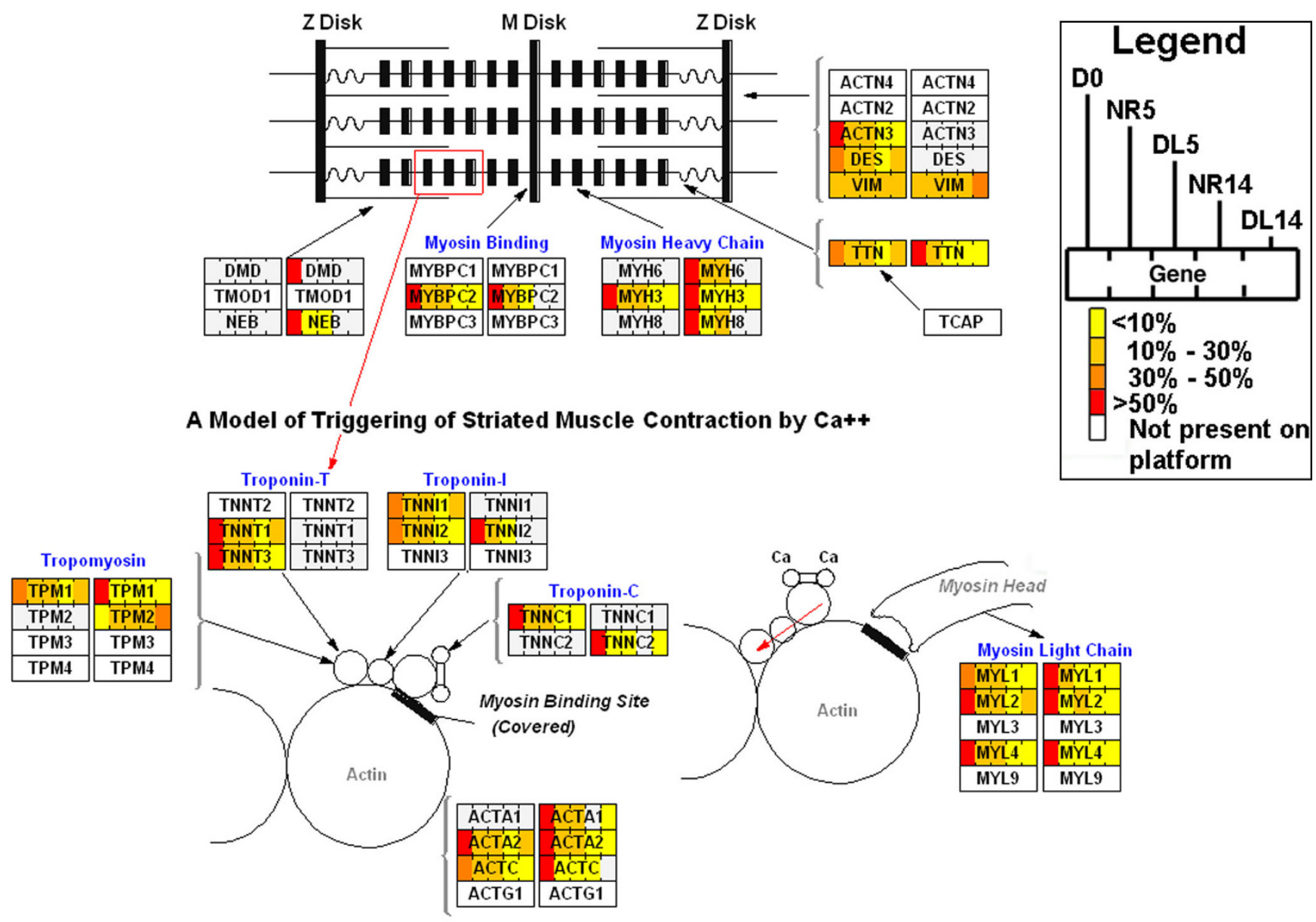

Figure 4

Schematic of down-regulated muscle contraction genes. Striated muscle contraction genes that were downregulated during limb regeneration. Each gene is represented by two boxes that denote proportional expression among Day 0, NR5, DL5, NR I4, and DLI 4 samples. The left box reports hybridization intensity from the microarray experiment and the right box reports normalized count data from the 454 cDNA sequencing experiment. Figure 4 was modified from a MAPP originally created by Joanna Fong and Nathan Salomonis.

and 17 were more abundant in DL5 limbs, and these differences were small in terms of fold-level change $(<3$-fold difference between NR5 and DL5; Additional file 3). Eighteen of these genes exhibited significant sequence similarity to human or salamander presumptive gene sequences; the others are unknown. The genes with significantly more transcripts in NR5 limbs are associated with intracellular (for example dnase1l3, uap1, acy3, nans, myl4) and extracellular functions, including membrane proteins (for example psca, umod, and emp1) and collagen binding (serpinh1). The genes with significantly more transcripts in DL5 limbs are associated with extracellular functions or the immune response (for example igll1, CD74, hmox1, neil1, marco, sftpd, mmp9, $m r c 1)$. All but one of the signifi- cant 5 dpa genes showed the same directional deviation at $14 \mathrm{dpa}$; myl1was 1.5-fold higher in the NR limb at $5 \mathrm{dpa}$, but 2.2-fold lower at $14 \mathrm{dpa}$. Thus, as was observed when comparing DL5 and NR5 mRNA abundances with baseline levels, relatively few gene expression differences were identified between NR and DL limbs at $5 \mathrm{dpa}$, and the magnitude of these differences was small. These results further support the idea that transcription during limb regeneration is predominantly nerve-independent at 5 dpa.

Whereas only 33 transcriptional differences were observed between morphologically similar DL and NR limbs at $5 \mathrm{dpa}, 282$ differences were detected at $14 \mathrm{dpa}$ 
(Additional file 4). $\mathrm{K}$-means cluster analysis of these genes with significant human protein hits highlighted three clusters wherein genes exhibited similar patterns of expression (Figure 5). Genes in Cluster 1 presented expression patterns with transcript abundances above baseline in NR14 limbs and abundances below baseline levels in DL14 limbs. Genes associated with cell cycling, a well-established characteristic of blastemal cells, were highly enriched in Cluster $1(n=26)$. Over $50 \%$ of the genes in Cluster 1 are predicted to localize to the nucleus, including several transcriptional regulators $(m s x 2$, id 3 , tmpo, atf5, rbm15, spen, parp1, and tardbp). Thus, many of the genes in Cluster 1 have functions that are consistent with blastema formation and outgrowth in NR limbs.

Genes from Clusters 2 and 3 were generally expressed in the same direction between NR14 and DL14 limbs; however, the magnitude of expression differed. Genes in Cluster 2 presented transcript abundances that generally exceeded baseline levels, with higher levels observed in DL14 limbs. This pattern suggests that most of these genes were activated in the same direction in the presence or absence of nerves, but denervation caused higher transcript abundances. Twenty-two percent of the genes in Cluster 2 are associated with the GO term cellular response to stimulus $(n=14)$ and a significant proportion localized to the lysosome $(n=6)$, including lgmn, ctsk, ctss, asah, atp6v0d1, and neu1. Genes in Cluster 3 presented transcript abundances that were generally lower than baseline levels, with much lower levels observed in NR14 limbs. With relatively few genes in this cluster, no biological process was identified as significantly enriched. However, inspection of the genes in Cluster 3 again supports the idea that some genes may function in muscle contraction (actc1, myh7, and fhl1) and tissue repair ( $h s p 27$ and hebp2). In summary, mRNA levels for genes from Clusters 2 and 3 were quantitatively affected by the presence or absence of a nerve.

\section{4 cDNA sequence analysis of nerve dependency}

To further explore nerve dependency and generate an unbiased collection of molecular probes for regenerating limbs, we sequenced cDNAs derived from the same RNA samples that were used in the microarray analysis. Over $1.7 \times 10^{6}$ reads were generated and this yielded approximately 90,000 to 230,000 high-quality sequence reads for each limb treatment, with an average of 215 base pairs in length (Table 2). More than half of the sequence reads correspond to mitochondrial transcripts and ribosomal RNA. This frequency of mtDNA transcripts (30\%) approximates the number sampled in an earlier EST screen of the Ambystoma genome [42]. The number of rRNA transcripts was higher than expected. Assembly of all high-quality cDNA reads yielded 429,086 unique sequences. These sequences were assembled with previous EST contigs to

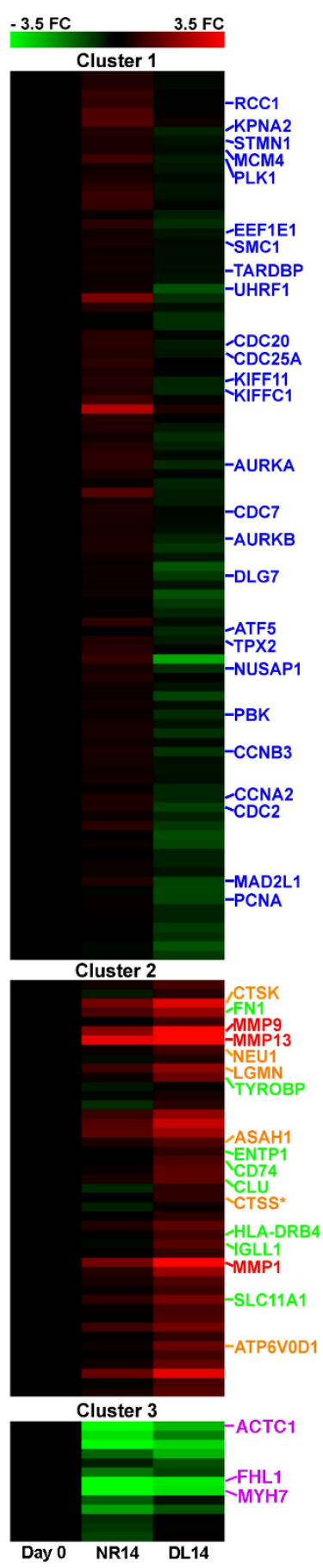

\section{Figure 5}

Clustering of genes identified as significant from the comparison of NRI 4 and DLI 4 limbs. Fold change values are relative to baseline levels at Day 0 . Blue-coded genes are cell cycle associated; orange-coded genes localize to the lysosome; green-coded genes are associated with inflammatory responses; red-coded genes are matrix metalloproteinases; purple-coded genes are associated with muscle. Genes coded $*$ are associated with inflammation and localize to the lysosome. 
Table 2: 454 DNA sequence reads that were generated for each cDNA limb library

\begin{tabular}{lcccccc}
\hline & Day 0 & NR5 & DL5 & NRI4 & DLI4 & totals \\
\hline Total Reads & 312258 & 216281 & 220561 & 393012 & 578787 & 1720899 \\
Filtered & 19459 & 14390 & 18918 & 22679 & 88387 & 163833 \\
mtRNA/rRNA & 168954 & 111490 & 92136 & 171046 & 256684 & 800310 \\
Final Reads & 123845 & 90401 & 109507 & 199287 & 233716 & 756756 \\
\hline
\end{tabular}

produce 61,127 contigs each containing at least two overlapping sequences. The distribution of contig lengths is shown in Figure 6. All contigs and singletons were searched against NCBI databases to identify significant similarity matches that would suggest presumptive gene identities. Ambystoma contigs and singletons yielded 25,446 significant hits to sequences in the human RefSeq database (BLASTx, $e<1 \times 10^{-7}$ ), including 9411 unique human genes. Figure 7 shows the distribution of percent coverage to predicted human RefSeq proteins. Interestingly, 7130 Ambystoma queries that did not show significant amino acid sequence identity to a human reference sequence did show significant nucleotide identity to a Xenopus sequence. Assembly of new 454 cDNA sequences with existing EST contigs from the Ambystoma EST database more than doubled (3935 to 9411) the number of non-redundant human- $A$. mexicanum orthologous sequences. This increase in sequence content was even among 10 GO functional categories that are relevant to salamander wound healing and regeneration (Table 3). Assuming that many of the anonymous 454 contigs and singletons $(>300,000)$ that were generated correspond to functional genes, significantly more than 10,000 different transcripts are expressed during the first two weeks of axolotl limb regeneration.

\section{mRNA abundance estimates and gene discovery from $\mathbf{4 5 4}$} cDNA sequence data

The number of times that a non-redundant transcript was sampled by $454 \mathrm{cDNA}$ sequencing was used to estimate
mRNA abundances. The transcript counts for 1150 Ambystoma EST contigs (genes) differed significantly among limb cDNA pools that were created for each of the limb types (Additional file 5). It was possible to assign a putative ortholog to 563 of these genes; the remaining genes were considered anonymous. This final list of genes was compared with the significant gene lists from the microarray analysis. It was determined that for 271 of the 1150 significant genes from the 454 cDNA sequencing analysis, a portion of the gene sequence was represented by a probe set on the Ambystoma GeneChip. Of these, 104 genes were identified as significant by both methodologies and mRNA abundances for these genes were highly positively correlated (Additional file 6; median Spearman's correlation $=0.87)$. The 167 genes found to be significant by 454 cDNA sequencing, but not by microarray analysis, were mostly characterized by low fold changes from baseline (median fold change as estimated from 454 cDNA sequencing counts $=1.75$ ); or conversely, registered low hybridization intensities in the microarray analysis (median rank among 4844 probe sets $=343$ ).

Gene functions that were identified as significantly enriched by microarray analysis were also identified as significant by 454 cDNA sequencing. For example, the muscle contraction GO term was identified as highly enriched and the underlying genes were similarly downregulated relative to baseline (Table 4; Figure 4; Additional file 6). Also, genes sampled most often from NR14 limbs were associated with DNA metabolism, a biological

Table 3: Gene ontology breakdown of the 94 I I salamander genes with presumptive human orthologs

\begin{tabular}{llcc}
\hline Ontology & Level & Old annotations & New annotations \\
\hline cell cycle & BP3 & 226 & 438 \\
metabolism & BP2 & 1889 & 3982 \\
cell motility & BP3 & 62 & 126 \\
mophogenesis & BP2 & 109 & 272 \\
development & BPI & 342 & 795 \\
response to stress & BP2 & 219 & 469 \\
cell death & BP3 & 142 & 312 \\
catalytic activity & MFI & 1275 & 2855 \\
transcription factor activity & MF2 & 112 & 344 \\
\hline
\end{tabular}

The table shows the number of Ambystoma ESTdb contigs with gene ontology annotations before and after 454 DNA sequencing. The total is less than the sum of each category because several genes may belong to multiple categories. $\mathrm{BP}=$ biological process. MF $=$ molecular function. 


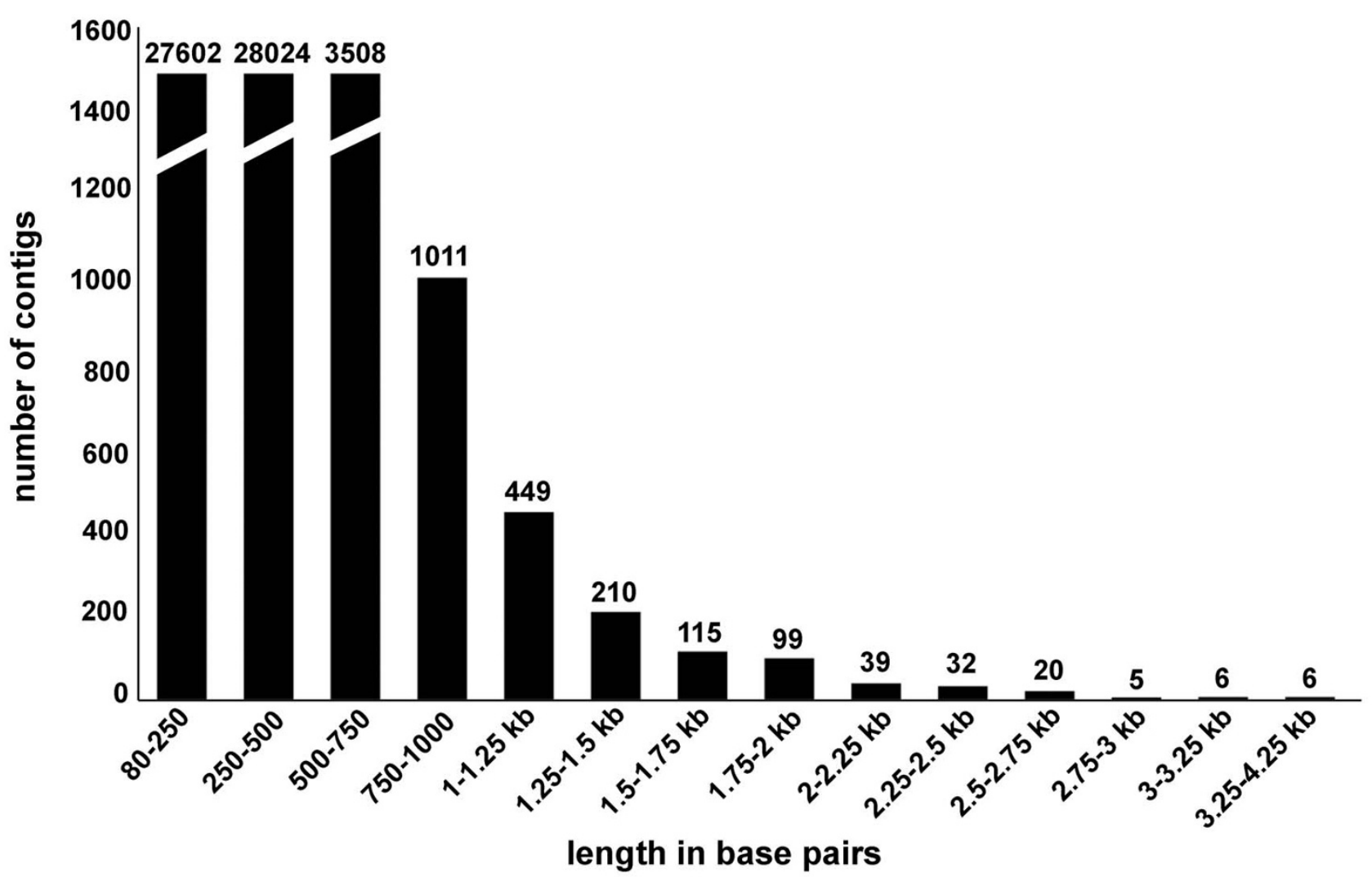

Figure 6

Bar graph showing contig lengths. Distribution of sequence lengths for each of the 61,127 contigs.

process associated with cell cycling (Table 4), and transcripts for genes associated with cell proliferation and cell cycle progression (for example pcna, smc1, ctps, umod, psca, smc1l1, rad21) were either sampled more often among NR limbs or were only sampled from NR limbs (Additional file 5). Thus, 454 cDNA sequencing also identified genes in NR limbs that are consistent with blastema formation. Several functional terms that were not identified by microarray analysis were identified as enriched by 454 cDNA sequencing. Transcripts for 40 genes associated with macromolecule metabolism were most abundant in NR5 limbs compared with other limbs. Transcripts for 12 genes associated with macromolecule catabolism were most abundant in DL5 limbs, including $m m p 1, m m p 3 /$ $10 a, m m p 3 / 10 b, m m p 9$, and $m m p 13$. This suggests that the presence or absence of nerves differentially affects transcriptional responses and regulation at $5 \mathrm{dpa}$. Also, 454 cDNA sequencing identified additional psca-like genes that were not represented on the GeneChip, and these were also differentially expressed between NR5 and DL5 limbs. These and other examples suggest that $454 \mathrm{cDNA}$ sequencing complemented the microarray analysis by providing deeper sampling of transcriptional programs and associated biological processes. This revealed more candidate nerve-dependent gene expression changes at the earlier $5 \mathrm{dpa}$ time point than was revealed by microarray analysis.

In addition to providing estimates of mRNA abundance, 454 cDNA sequencing also discovered new gene sequences for the Mexican axolotl. These include genes that are known to affect developmental processes in other vertebrate models: notch $(1,2,3,4)$, nrg1, bmp1, wnt4, ctnna1, btnna1, dkk1, axin 1, nrg1, fgf10, sirt $(1,2,5,6)$, stats $(1,2,3,5,6)$, sema4f, tf, sfrp $(1,2,5)$, rara, rarg, rxr, pdgf, acurI (IB, IIA, IIB), bmprI, bmprII, smad (1, 2, 4, 5, 7, 9), efna1, ntn1, slit2, slit3, robo1, and robo2. Most of these genes were sampled less than 10 times and thus appear to be expressed at low levels. Other developmental genes that have not been previously associated with limb regeneration were sampled many more times than these candidates, and for the following examples, counts varied significantly among limb cDNA libraries. These include $m d k$, fliI, tagln2, $d d x 5$, umod, and cnot1 (Additional file 5). Also, numerous retroelement-associated sequences were sampled differentially between DL and NR limbs (Table 


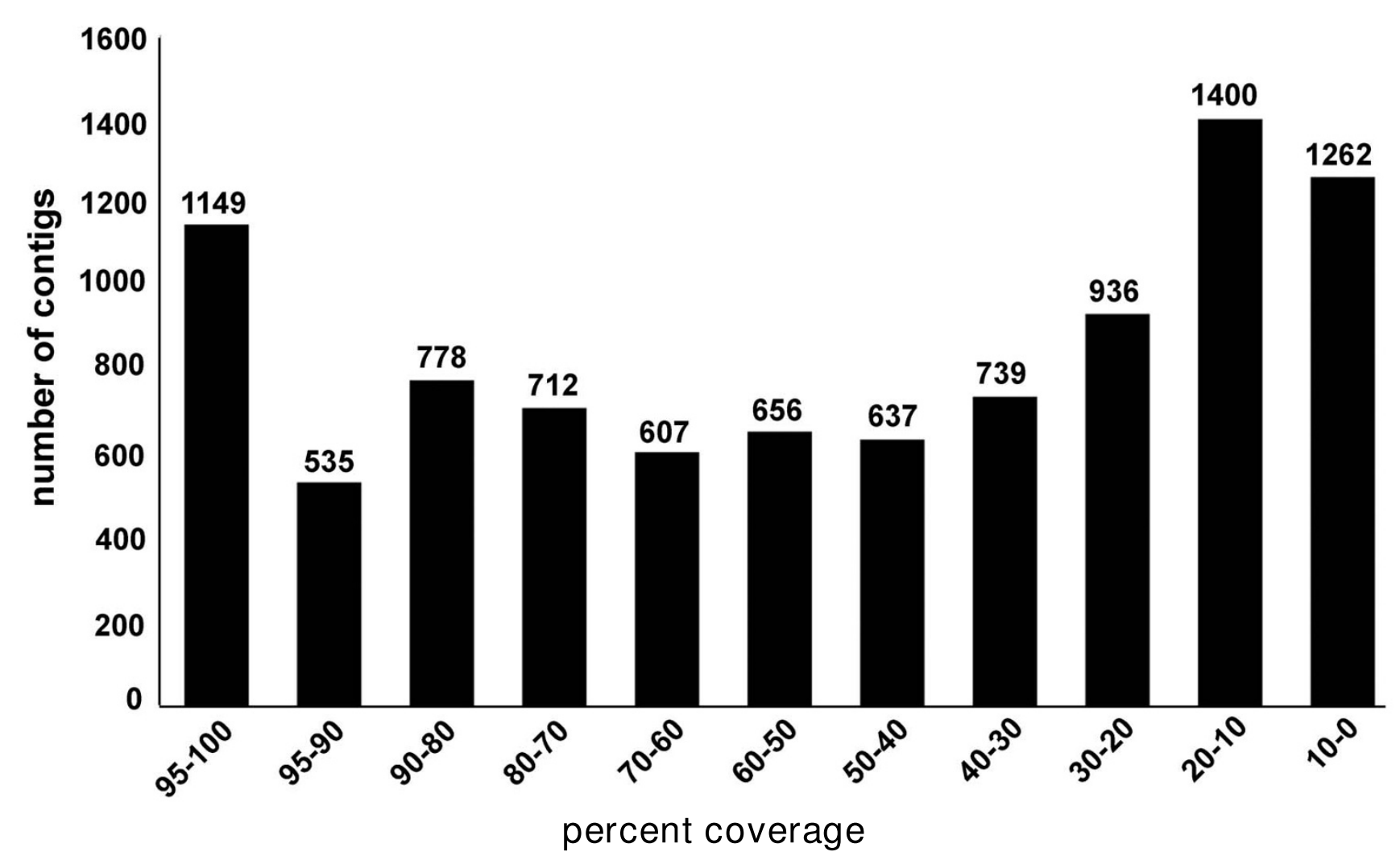

\section{Figure 7}

Bar graph showing percent coverage of human proteins. The distribution of the percent coverage for each of the unique 94 II human proteins with presumptive salamander orthologs.

5). Overall, the 454 sequencing approach verified the primary results from the microarray analysis and identified many new candidate genes and functional pathways that are associated with limb regeneration.

\section{Discussion}

Microarray analysis and 454 cDNA sequencing were used to identify nerve-dependent and independent gene expression changes during limb regeneration in the Mexican axolotl. The results show that limb regeneration is associated with thousands of transcriptional changes.

Table 4: Gene ontology results from 454 sequencing

\begin{tabular}{lll}
\hline cDNA library & Most significant GO term & p-value \\
\hline Day 0 $(N=127)$ & striated muscle contraction $(N=17)$ & $1.75 E-27$ \\
NR5 $(N=84)$ & macromolecule metabolism $(N=40)$ & $1.37 \mathrm{E}-05$ \\
DL5 $(N=59)$ & macromolecule catabolism $(N=12)$ & $6.21 \mathrm{E}-08$ \\
NRI4 $(N=54)$ & DNA metabolism $(N=6)$ & $2.00 \mathrm{E}-02$ \\
DLI4 $(\mathrm{N}=43)$ & protein biosynthesis $(\mathrm{N}=14)$ & $1.44 \mathrm{E}-17$
\end{tabular}

Gene ontology analysis of 465 genes with presumptive human orthologs identified by 454 DNA sequencing. Only the most significant gene ontology category was selected for the table.
Considerable similarity was observed between the DL and NR transcriptional programs at 5 and 14 dpa. For example, genes that are critical to wound healing were upregulated in both limb types (Table 6) while genes that are associated with muscle structure and function were downregulated (Figure 4). Many of the transcriptional changes that were observed at 5 dpa were also observed at $14 \mathrm{dpa}$. Thus, many aspects of early limb regeneration are accomplished in the absence of nerves. However, gene expression differences were identified between DL and NR limbs at 5 and $14 \mathrm{dpa}$. Many of the transcriptional differences correlated with blastema formation; cell numbers increased in NR limbs after $5 \mathrm{dpa}$ and this yielded a distinct transcriptional signature of cell proliferation in NR14 limbs. Overall, this study identified genes that are associated with wound healing, early events of blastema formation, and subsequent blastema cell proliferation and outgrowth. Below, we discuss and expand upon these primary results and highlight genes whose functions appear to be important for understanding the basis of nerve dependency and limb regeneration. 
Table 5: Significantly changed retrovirus-like genes

\begin{tabular}{|c|c|c|c|c|c|c|c|}
\hline Contig & Best hit & Gene Name & NR5 & DL5 & NRI4 & DLI4 & C \\
\hline |0177_Contig| & $\underline{X P} 001201693$ & rev. transcriptase-like & 10 & 2 & 0 & 0 & 0 \\
\hline 10435_Contigl & ABB52637 & envelope polyprotein & 19 & 7 & 0 & 2 & 0 \\
\hline 10953_Contig8 & NP 055405 & end. retroviral w & 5 & 15 & 0 & I & 0 \\
\hline |09875_Contig| & AAD 19348 & rev. transcriptase-like & 0 & 0 & 10 & 0 & 0 \\
\hline I10157_Contig5 & $\overline{N P \quad 079357}$ & hyp. prot. LOC57523 & 7 & 20 & 42 & 6 & 0 \\
\hline 126954_Contig I7 & AAM34208 & polyprotein & 12 & 22 & 32 & 6 & 8 \\
\hline |28|3_Contig| & NP 003409 & zinc finger protein 9 & 14 & 37 & 67 & 20 & 37 \\
\hline 154450_Contig I 6 & XP 945963 & retrotransposon-like I & 5 & 27 & 11 & 2 & 10 \\
\hline |74946_Contigl & $\overline{B A C 82626}$ & pol-like protein & 0 & 0 & 11 & 0 & 0 \\
\hline |85474_Contig|40 & $\overline{X P 790598}$ & Helitron transposon & 81 & 276 & 314 & 106 & 59 \\
\hline | 95627_Contig| & XP 692835 & gypsy I polyprot. & 0 & 0 & 11 & 0 & 0 \\
\hline 218328_Contigl & XP 945963 & retrotransposon-like I & 0 & 0 & 13 & 0 & 0 \\
\hline 2194_Contigl & $X P 001345076$ & pol polyprotein & 17 & 0 & 0 & 0 & 0 \\
\hline 23276_ContigI & NP 006798 & chromobox hom. I & 14 & 0 & 0 & 0 & 0 \\
\hline 23893_Contigl & $\mathrm{ZP} 01758189$ & NBB2750 hyp. protein & 12 & 0 & 0 & 0 & 0 \\
\hline 32735_Contigl & $\overline{X P \quad 001201693}$ & rev. transcriptase-like & 12 & 0 & 0 & 0 & 0 \\
\hline 331680_ContigI & $\overline{X P 001336840}$ & lambda-recomb.-like & 2 & 12 & 30 & 11 & 6 \\
\hline 352970_Contigl & AAD02928 & rev. transcriptase & 0 & 0 & 0 & 0 & 12 \\
\hline 39722_Contigl & XP 687309 & rev. transcriptase & 98 & 117 & 138 & 51 & 92 \\
\hline 42238_Contig456 & NP 055883 & paternally exp. 10 & 41 & 2 & 10 & 3 & 12 \\
\hline 42238_Contig60 & NP 055883 & paternally exp. 10 & 7 & 35 & 37 & 10 & 27 \\
\hline 89909_ContigI & BAD72127 & rev. transcriptase & 0 & 12 & 0 & 0 & 0 \\
\hline 94735_Contig I & $\mathrm{XP} 001336840$ & lambda-recomb.-like & 0 & 12 & 0 & 0 & 0 \\
\hline
\end{tabular}

Genes identified as differentially expressed by 454 sequencing analysis that have high sequence similarity to retrovirus genes.

\section{Early wound-healing response during limb regeneration} Previous studies have documented anatomical similarities between innervated and denervated limbs at early stages of regeneration $[20,43,44]$. This study shows that there are also many transcriptional similarities. This suggests that many aspects of the early wound-healing phase of limb regeneration are not dependent upon post-amputation, nerve-derived factors (Table 6). Instead, humoral immune and local tissue responses appear to be key. Many genes that are associated with wound-healing and tissue-repair activities including stress, inflammation, cell survival, immunity, and extracellular matrix remodeling were upregulated from baseline in $5 \mathrm{dpa}$ limbs (Figure 2; Table $6)$. It is probably no coincidence that essentially all of the early stress-associated genes that were previously identified as significantly regulated (using the same Ambystoma GeneChip) during early spinal cord regeneration [37], and during the innate immune response of axolotls to a deadly viral pathogen [38], were also identified as significant in this study. Many of these genes appear to be expressed similarly in all vertebrates in response to stress, including junb, irf1, hmox1, apoE, mmps, ptx3, gal3, gadd $45 g$, and $t g f b$. Additionally, significantly more 'extracellular' genes were identified at $5 \mathrm{dpa}$ than expected by chance, including genes that code for matrix remodeling proteins and secreted molecules whose functions are associated with growth factor binding, cell signaling, survival, death, adhesion, migration, and proliferation. The early wound-healing response initiates local environmental changes of the injury site that are pivotal to subsequent phases of regeneration.

The 5 dpa time point was chosen in this study to identify critical nerve-dependent signaling events that are stimulated within the first few days of regeneration (see [11]). Comparison of DL5 and NR5 data revealed few overall gene expression differences. The 5 dpa time point captured many transcriptional responses that are induced by injury and/or amputation but relatively few that are associated with known or suspected neurotrophic signaling pathways. More comprehensive sampling and deeper sequencing is needed to detail early nerve-dependent transcriptional responses because several genes that are known to be nerve-responsive during the wound-healing phase were not identified in this study (for example sp9, [11]; prrx1, tbx5, [10]).

\section{Downregulation of genes associated with differentiated muscle}

This study documented dramatic decreases in the relative abundance of mRNAs coding for skeletal muscle contractile proteins, including myosins, actins, actinins, titin, tropomyosins, and troponins. Many of these changes were also detected by 454 cDNA sequence analysis (Figure 4). This strong, muscle-specific transcriptional signature was observed because approximately half of uninjured forelimb nuclei in 7 to $9 \mathrm{~cm}$ axolotls, and likely more than half the cross-sectional area, derive from muscle [45]. It is 
Table 6: Significantly changed wound-healing genes

\begin{tabular}{|c|c|c|c|c|c|c|c|}
\hline Probe ID & Best Hit & Symbol & NR5/C & DL5/C & NRI4/C & DLI4/C & Function \\
\hline SRV_0I35I_at & NP 002220 & JUNB & 4.60 & 4.74 & 2.35 & 3.46 & stress resp. \\
\hline SRV_10702_at & NP 000388 & CYBB & 2.84 & 4.11 & 1.73 & 2.46 & stress resp. \\
\hline SRV_00330_at & NP 000388 & CYBB & 2.39 & 3.46 & 1.58 & 2.23 & stress resp. \\
\hline SRV_03054_at & $\overline{N P \quad 006761}$ & MARCO & 2.00 & 3.11 & 1.83 & 3.01 & stress resp. \\
\hline SRV_00I30_a_at & NP 000032 & APOE & 1.90 & 2.49 & 2.36 & 4.28 & stress resp. \\
\hline SRV_00442_at & NP 000569 & SLCIIAI & 1.95 & 2.76 & 1.58 & 3.00 & stress resp. \\
\hline SRV_0I82I_at & NP 937758 & TYROBP & 1.98 & 2.45 & & 2.65 & stress resp. \\
\hline SRV_03023_a_at & NP 006696 & GADD45G & 1.96 & 2.29 & & 2.01 & stress resp. \\
\hline SRV_02588_a_at & NP 005558 & LGALS3BP & 1.91 & 2.37 & & 1.59 & stress resp. \\
\hline SRV_0II77_a_at & NP 001091645 & ENTPDI & 2.39 & 2.23 & & 1.58 & stress resp. \\
\hline SRV_02586_at & NP 005558 & LGALS3BP & 1.79 & 2.25 & & 1.81 & stress resp. \\
\hline SRV_II767_a_at & $\mathrm{NP} 001020466$ & IFITM5 & 1.75 & 1.63 & 1.56 & & stress resp. \\
\hline SRV_02724_at & NP 005902 & MAT2A & 2.60 & 1.60 & 1.78 & & stress resp. \\
\hline SRV_01617_a_at & NP 002843 & PTX3 & 4.30 & 3.78 & & & stress resp. \\
\hline SRV_02002_at & NP 001020366 & CESI & 2.36 & 3.01 & & & stress resp. \\
\hline SRV_0322I_a_at & NP 060049 & DMBTI & 1.81 & 2.50 & & & stress resp. \\
\hline SRV_07036_at & NP 000567 & ILIB & 1.70 & 1.53 & & & stress resp. \\
\hline SRV_02516_at & NP 005338 & HSPA5 & 1.65 & & & & stress resp. \\
\hline SRV_02965_at & NP 006519 & TFPI2 & 2.22 & & & & stress resp. \\
\hline SRV_12417_at & NP 006087 & NDRGI & 2.57 & & & & stress resp. \\
\hline $\mathrm{AH} \_$at & NP 006588 & HSPA8 & 1.52 & & 1.67 & & stress resp. \\
\hline SRV_0I846_at & $\overline{N P \quad 003352}$ & UMOD & 2.27 & & 2.00 & & stress resp. \\
\hline SRV_0I294_at & NP 002023 & FTHI & & 1.67 & & 2.01 & stress resp. \\
\hline SRV_0I385_at & NP 002293 & LECT2 & & 3.93 & & 7.38 & stress resp. \\
\hline SRV_0I840_at & NP 003346 & UCP2 & & 1.53 & & 2.13 & stress resp. \\
\hline SRV_II406_at & NP 002341 & LYN & & 1.74 & & 1.72 & stress resp. \\
\hline SRV_II583_at & NP 002960 & MAPKI 2 & & 2.04 & & 1.92 & stress resp. \\
\hline SRV_07726_a_at & NP 001034485 & MPEGI & & 1.77 & & 2.27 & stress resp. \\
\hline SRV_04367_a_at & NP 064455 & IGLLI & & & & 2.29 & stress resp. \\
\hline SRV_04710_at & NP 078884 & NEILI & & & & 1.93 & stress resp. \\
\hline SRV_10936_at & NP 000945 & PTGDS & & & & 4.19 & stress resp. \\
\hline SRV_00002_s_at & NP 064455 & IGLLI & & & & 2.09 & stress resp. \\
\hline SRV_00078_at & NP 064455 & IGLLI & & & & 2.43 & stress resp. \\
\hline SRV_0II99_a_at & NP 001822 & CLU & & & & 2.36 & stress resp. \\
\hline SRV_02442_a_at & NP 005092 & GIP2 & & 2.56 & & & stress resp. \\
\hline SRV_026II_a_at & NP 005618 & SGK & & 1.57 & & & stress resp. \\
\hline SRV_I3637_a_at & NP 066362 & IFITM3 & & 1.51 & & & stress resp. \\
\hline SRV_01323_a_at & NP 002124 & HMOXI & 10.05 & 18.24 & 5.13 & 8.53 & antioxidant \\
\hline SRV_00444_a_at & NP 000572 & GPXI & 1.67 & 1.51 & & & antioxidant \\
\hline SRV_0I423_a_at & NP 002412 & MMPI & 26.65 & 37.91 & 2.94 & $11.4 \mid$ & ECM remod. \\
\hline SRV_01428_x_at & NP 002416 & MMPIO & 22.86 & 30.96 & 2.87 & & ECM remod. \\
\hline SRV_0I430_at & NP 002418 & MMPI3 & 22.54 & 34.09 & 9.04 & 24.97 & ECM remod. \\
\hline SRV_0I425_at & NP 002418 & MMPI3 & 19.64 & 23.46 & 3.10 & 2.60 & ECM remod. \\
\hline SRV_II420_at & $\overline{N P 07 / 405}$ & MMP27 & $16.7 \mid$ & 23.32 & & 4.52 & ECM remod. \\
\hline SRV_02399_a_at & NP 004985 & MMP9 & 15.22 & 23.05 & 3.51 & 15.69 & ECM remod. \\
\hline SRV_II423_at & NP 002418 & MMPI3 & 6.79 & 8.48 & & 2.20 & ECM remod. \\
\hline SRV_II4I7_a_at & NP 002412 & MMPI & 6.42 & 8.48 & & & ECM remod. \\
\hline SRV_12016_at & NP 004521 & MMP2 & & & 1.71 & 2.49 & ECM remod. \\
\hline SRV_0224I_at & NP 004521 & MMP2 & & & 1.66 & 2.34 & ECM remod. \\
\hline SRV_10485_at & NP 004521 & MMP2 & & & & 2.11 & ECM remod. \\
\hline SRV_00453_a_at & NP 000651 & TGFBI & 2.40 & 2.32 & & 1.93 & multifunctional \\
\hline SRV_00328_at & NP 000387 & CTSK & 7.03 & 8.07 & 4.86 & 19.35 & lysosome \\
\hline SRV_00327_a_at & NP 000387 & CTSK & 3.72 & 4.73 & 2.94 & 8.23 & lysosome \\
\hline SRV_00326_a_at & NP 000387 & CTSK & 3.19 & 3.78 & 2.84 & 6.47 & lysosome \\
\hline SRV_02600_a_at & $\mathrm{NP} 001008530$ & LGMN & 2.16 & 2.81 & 1.80 & 3.66 & lysosome \\
\hline SRV_05534_at & NP 796377 & RAB7B & 1.91 & 1.99 & & 1.83 & lysosome \\
\hline SRV_02353_a_at & NP 004853 & LITAF & 1.88 & 2.29 & & 1.75 & lysosome \\
\hline SRV_0II34_at & NP 001684 & ATP6VIB2 & 1.83 & 2.24 & & 1.96 & lysosome \\
\hline SRV_02294_at & $\overline{N P 004682}$ & ATP6V0DI & 1.73 & 2.33 & & 2.73 & lysosome \\
\hline
\end{tabular}


Table 6: Significantly changed wound-healing genes (Continued)

\begin{tabular}{|c|c|c|c|c|c|c|c|}
\hline SRV_14287_a_at & NP 666023 & CTSL & 1.66 & 2.23 & & 2.03 & lysosome \\
\hline SRV_0260I_at & NP 001008530 & LGMN & 1.66 & 2.09 & 1.58 & 2.44 & lysosome \\
\hline SRV_05336_a_at & NP 001903 & CTSL & & 1.75 & & 1.69 & lysosome \\
\hline SRV_00294_s_at & NP 000299 & PPGB & & 1.67 & & 2.12 & lysosome \\
\hline SRV_0II35_a_at & NP 001685 & ATP6V0C & & 1.62 & & & lysosome \\
\hline SRV_0I242_a_at & NP 001900 & CTSD & & 1.62 & & 2.25 & lysosome \\
\hline SRV_0I559_a_at & NP 002769 & PSAP & & 1.58 & & 1.61 & lysosome \\
\hline SRV_00355_at & NP 000425 & NEUI & & 1.57 & & 1.87 & lysosome \\
\hline SRV_02|4I_at & NP 004306 & ASAHI & & 1.56 & & 2.15 & lysosome \\
\hline SRV_0966I_at & NP 001805 & CTSC & & 1.52 & & 1.99 & lysosome \\
\hline SRV_0I558_at & NP 001035931 & PSAP & & & & 2.71 & lysosome \\
\hline SRV_00334_a_at & NP 001073279 & GLBI & & & & 1.64 & lysosome \\
\hline SRV_I070I_at & NP 000387 & CTSK & & & & 1.58 & lysosome \\
\hline
\end{tabular}

Fold-level change of upregulated genes that have functions associated with a wounding response (identified by microarray analysis).

unlikely that the downregulation of muscle genes is due to retraction of the muscle towards the shoulder because muscle transcripts are much more downregulated at 14 dpa than 5 dpa in both denervated and innervated limbs. Considering that limb tissue samples in this study included $\sim 1 \mathrm{~mm}$ of undamaged tissue proximal to the amputation plane, the results suggest that injury to skeletal muscle induces tissue-wide loss of muscle contractile transcripts. It is possible that the decrease in muscle transcripts is due to muscle wasting, caused by a lack of mechanical stress. It is interesting to speculate that this response maybe associated with the degeneration or cellularization of multinucleated muscle fibers into mononucleated cells, which occurs in both denervated and innervated amputated limbs [41,46-50]. It is interesting to note that muscle-specific genes, including actc1, actn2, atp2a2, my1pf, tncc, tnni2, tnni3, are downregulated during early stages of mammalian skeletal muscle regeneration [51], and this is accomplished without blastema formation. Skeletal muscle regeneration in mammals and other vertebrates involves resident stem (satellite) cells $[52,53]$. It is possible that muscle-specific genes are downregulated as an integral step of a conserved, skeletal muscle regeneration program of vertebrates. Candidate transcriptional repressor genes were identified in this study including id 3 [54], tardbp [55], cnot [56], $m s x 1$ [6,57] and $m s x 2$. It will be important in future studies to determine if the dramatic decrease in muscle transcripts is due to activation of muscle stem (satellite) cells, muscle loss, muscle dysfunction/ wasting, or whether these transcriptional patterns have an active role in regeneration.

\section{Genes associated with epigenetic reprogramming and genomic stability}

Blastema formation requires a large number of progenitor cells derived from quiescent stem cells or differentiated cell types. It is generally known that reprogramming of differentiated cells is accompanied by epigenetic changes such as histone and DNA modifications [58,59]. Few candidates have been identified previously as bringing about epigenetic changes necessary for cellular reprogramming during regeneration $[60,61]$. This study identified several genes whose functions are associated with epigenetic phenomena, including chromatin remodeling, DNA methylation, and transcriptional regulation. These include uhrf1 [62], lmnb2, parp1 [63], thymopoietin [64], and a gene with high sequence identity to SAM-dependent methyltransferases (Cluster_227434_Contig1; SRV_05867_a_at).

After cellular reprogramming and during limb outgrowth, blastemal cells undergo tremendous cell proliferation. During blastema cell proliferation, telomere lengths and overall genome stability must be maintained to prevent cell death. This study identified several candidate genes from NR14 limbs that are known to function in genome stability, telomere homeostasis, and DNA repair. These include parp1 [65], hmgb2 [66], fen1 [67], aurka [68], aurkb [69], and pif1, a DNA helicase that maintains genome stability and binds to telomerase from yeast to humans [70]. It is also important to note that many transcripts were identified from NR and DL limbs that code for retroelement components (Table 5; for example polyproteins, gag proteins, reverse transcriptases, and recombinases). Retrotransposons are normally transcriptionally silenced in differentiated somatic cells by epigenetic mechanisms, but become active upon changes in epigenetic status; these may also regulate nearby gene expression [71,72]. It is unclear if upregulation of retroelement transcripts affects genome stability and/or is necessary for regeneration.

\section{Genes associated with nerve-dependent blastema outgrowth}

In this study, blastemas were not observed in NR5 limbs or DL14 limbs, and only formed on NR14 limbs. Nervedependent limb outgrowth occurs as a result of blastemal cell proliferation. Two early cell proliferation biomarkers, umod and psca, were identified as significantly different between NR5 and DL5 limbs. umod probably locates to the wound epithelium as it is upregulated in apical skin cells during thyroid hormone-induced metamorphosis of 
axolotl epidermis (unpublished data). It is possible that psca is a membrane receptor of blastema cells because it shows structural similarity to prod1, a surface protein that is implicated in proximal-distal positional identity of blastemal cells during newt limb regeneration [73]. Most of the cell proliferation biomarkers were identified at 14 dpa, when a blastema was present in NR limbs but absent in DL limbs. Thus, between 5 and $14 \mathrm{dpa}$, blastemal cells underwent considerable cell proliferation in the presence of nerves. Because the limb blastema continues to expand after $14 \mathrm{dpa}$, the blastema-specific genes that were identified in this study are probably transcribed at much higher levels at later time points. A clear signature of cell proliferation, including genes that function in the cell cycle, mitosis, and nucleotide synthesis, was observed in NR14 limbs. In contrast, these genes were slightly downregulated in denervated limbs at this time (Table 1; Figure 5). Thus, transcripts associated with cell proliferation are maintained at steady state (no increased proliferation) in NR and DL limbs for at least five days. This early, nerveindependent portion of the limb regeneration program may allow time for re-innervation of the injury site and production of nerve-derived molecules in sufficient quantity to initiate and sustain blastemal cell proliferation.

Multiple gene products have been hypothesized to be neurotrophic factors provided by nerves to sustain blastema cell proliferation. These include growth-promoting factors such as fibroblast growth factors [11,31], substance P [74], neuregulin [33], and transferrin [32]. Transferrin and neuregulin were sampled by 454 sequencing, but were not identified as differentially expressed by our analysis. $f g f 8$ and $f g f 10$ were screened out of the microarray analysis due to low expression, but post-hoc analysis suggested that both are upregulated in NR14 limbs compared to control and DL14 limbs (Additional file 7). Expression of these molecules is known to be nervedependent in blastemas of Xenopus [75] and axolotls $[3,4,76]$. Other molecules that have previously been associated with the blastema during limb regeneration were not included in our statistical analyses due to low hybridization intensity, but were later found to be differentially expressed in NR14 limbs, including hoxd10, hoxa13, hoxa11, and msx1 (Additional file 7). Recently, Kumar et al [34] identified a growth-promoting extracellular ligand (nAG) that rescues aspects of nerve dependency of limb regeneration in newts. Probesets for $n A G$ are represented on the Ambystoma GeneChip and transcripts for this gene were sampled by $454 \mathrm{cDNA}$ sequencing. $n A G$ mRNA was transcribed at a high level in all tissues, but did not differ significantly between NR, DL, or control limbs. It is possible that the effects of $n A G$ and other neurotrophic candidates are associated with quantitative variation of mRNA transcript abundances over fine temporal and spatial scales. Such variation would have been missed in this analysis of three time points and sampling of mRNAs from heterogeneous tissues. Furthermore, it is possible that the increase in nAG immunoreactivity observed by Kumar et al [34] is regulated at the level of translation and would not be observed using microarray or sequencing approaches. Overall, we found that several, but not all, genes previously shown to be directly downstream of neurotrophic factors are expressed at higher mRNA levels in the blastema versus control and denervated samples.

Singer [17] emphasized that the neurotrophic factor underlying nerve dependency was growth promoting and quantitative in effect. He showed that the trophic effect of nerves could be titred by surgically manipulating the number of nerves innervating the limb [16]. Other lines of research showed that nerve-derived factors were not necessary for traversing cell cycle checkpoints, as an equivalent number of presumptive blastema cells are initially observed to enter $S$ phase in denervated and innervated limbs [21,77-79]. Instead, the neurotrophic factor appears to be necessary to complete the cell cycle and this may be non-trivial considering the cost of replicating a large salamander genome. These studies suggest that nerves either directly or indirectly provide limiting macromolecules that are needed to accomplish cell division. According to this reasoning and assuming a correlation between transcript and protein abundance for specific mRNA species, transcripts associated with nerve dependency would be expected to exceed baseline levels in NR limbs during regeneration, and decrease in abundance in DL limbs. This study identified many human-axolotl presumptive orthologs and anonymous axolotl transcripts that showed this pattern. For example, psat codes for a protein that regulates the second enzymatic step of the phosphorylated pathway in mammals, which produces L-serine [80]. PSAT expression (protein and mRNA) is high among cell types with high rates of proliferation, including cancer cell lines $[81,82]$. Strikingly, psat registered the largest mRNA abundance difference between NR14 and DL14 limbs among probesets on the Ambystoma GeneChip (8.2-fold change), and this result was verified by both $454 \mathrm{cDNA}$ sequencing (NR14 = 20.1, DL14 = 3) and real-time PCR (8.37-fold change; data not shown). We also found that the third enzyme in the phosphorylated pathway, $p s p h$, was 3.58-fold higher in NR14 versus DL14 by real-time PCR (data not shown). PSAT and PSPH may have neurotrophic potential but more likely function to provide proliferating cells with a limiting and conditionally important substance (L-serine) that is required for synthesis of macromolecules, amino acids, and purines that are needed to accomplish mitosis [80]. The fact that macromolecular synthesis and cell proliferation are both depressed in denervated limbs [83-86] supports the idea that PSAT activity is associated with nerve-derived factors that contribute to blastema outgrowth. 


\section{Comparison of microarray and cDNA sequencing approaches}

Microarray analysis and 454 cDNA sequencing offer different advantages for dissecting complex biological processes. The strength of microarray analysis is the precision that this approach provides for estimating transcript abundances for a specific panel of genes. Such gene panels provide standardized markers for identifying shared and unique patterns of transcription among experiments. In turn, identification of such patterns provides systemslevel insight. For example and as was discussed above, cross-experiment comparisons of axolotl transcription helped distinguish general stress responses from local regenerative responses. A relatively conservative fold level threshold ( $>1.5$-fold) was used in this study to identify significant genes in the microarray analysis and lowly expressed genes (in the lowest quartile) were removed from consideration. These conservative approaches potentially exclude important genes but likely discover 'real' transcriptional differences between samples. A lower threshold could be applied to extract more information from the dataset and future studies would likely benefit by increasing replication of GeneChips to detect significant differences for lowly expressed genes. With respect to 454 cDNA sequencing, two goals were accomplished: gene discovery and estimation of transcript abundance. However, accomplishment of both goals required a trade-off in the allocation of resources toward deep sequencing versus replication. Sequencing resources were used to deeply sequence Day $0, N R$, and DL CDNA libraries instead of shallowly sequencing replicate libraries for these time points. This strategy identified thousands of new gene sequences that will greatly enrich future regeneration studies. Future studies will benefit from experimental designs that replicate deep sequencing of cDNA libraries and this will be possible as sequencing costs decrease. Still, it was encouraging to find in this study that $38 \%$ of genes that were identified as differentially expressed by 454 cDNA sequencing and found on the microarray GeneChip were identified as significant by both of these technologies, and transcript abundances for these genes were highly positively correlated.

\section{Conclusion}

This study addressed the nerve dependency of limb regeneration by characterizing downstream cellular events that are affected when an intact nerve supply is removed from an amputated salamander limb. Microarray analysis showed that the early wound response is largely nerveindependent, but transcriptional profiles diverge between denervated and innervated limbs when the innervated limb starts to regenerate. Pyrosequencing supported these microarray results while substantially increasing sequence information from the salamander transcriptome. This study shows the utility of next-generation sequencing platforms for gaining transcriptome information [87-89]. This new DNA sequence information will greatly enrich future regeneration studies using the axolotl.

\section{Methods \\ Animal procedures}

Mexican axolotls were obtained from the Ambystoma Genetic Stock Center at the University of Kentucky. Siblings were reared individually under $a b$ libitum conditions to 60 to $70 \mathrm{~mm}$ snout to vent length. The $3^{\mathrm{rd}}, 4^{\text {th }}$, and $5^{\text {th }}$ spinal nerves that enter the left limb were severed at the brachial plexus behind the shoulder. Denervated left and innervated right limbs were amputated at mid-stylopod and allowed to regenerate for 5 and 14 days. Animal care and use procedures were approved by the University of Kentucky Internal Animal Care and Use Committee.

\section{Histology}

Limbs were collected at 5 and $14 \mathrm{dpa}$ and fixed in $4 \%$ paraformaldehyde, $1 \times$ PBS overnight at $4^{\circ} \mathrm{C}$. Tissues were cryoprotected in sucrose, embedded in TissueTek, and sectioned at $16 \mu \mathrm{m}$. Eosin $\mathrm{Y}$ and Gill's hematoxylin \#2 (Sigma-Aldrich, St. Louis, MO, USA) were used to stain cytoplasm and nuclei. DIC and brightfield images were taken on an Olympus AX80 microscope (Center Valley, PA, USA).

\section{RNA extraction and microarray analysis}

DL and NR limbs were collected approximately $1 \mathrm{~mm}$ proximal to the amputation plane $5 \mathrm{dpa}$ and $14 \mathrm{dpa}$. Nine animals were used for each time point and limbs were pooled into three groups of three. Left and right limbs were paired within animals when possible in making the pools for the 5 and 14 dpa time points. The day 0 pools were created using only the right limbs of nine different individuals that were collected within minutes following limb amputation. RNA was extracted using Trizol Reagent (Invitrogen, Carlsbad, CA, USA) followed by RNeasy minicolumns (Qiagen, Valencia, CA, USA). RNA quality was assessed by spectrophotometry using a Nanodrop ND1000 (Nanodrop, Wilmington, DE, USA) and run on a Bioanalyzer 2100 (Agilent, Santa Clara, CA, USA). The Ambystoma microarray platform was produced by the Voss lab and Affymetrix and has been described elsewhere $[35,37]$. Total RNA was used to produce cRNA probes for GeneChip hybridizations (Affymetrix, Santa Clara, CA, USA) at the University of Kentucky Microarray Core Facility according to standard Affymetrix protocols. Probe level quality control analyses were performed as described in [37]. Data processing and statistical analysis was performed using the Affy Bioconductor package for the R statistical environment [90]. Background correction, normalization, and probe set summarization were performed via the robust multi-array average (RMA) algorithm of [91]. Correlation matrices (Pearson's $r$ ) for 
replicate GeneChips at the probe-set level were produced to assess correlation between GeneChips (minimum $r=$ 0.9787, maximum $r=0.9952$ ). Probe-sets were removed if mean signal intensity was less than the mean of the lowest quartile across all 15 GeneChips (mean \pm standard deviation $=7.748 \pm 0.031$ ). Some microarray technologies may provide unreliable hybridization estimates for lowly expressed genes [92]. For this reason, a stringent cut-off was applied that removed the bottom quartile of genes for significance testing. Probe-set filtering yielded 3656 probe-sets for significance testing.

\section{Microarray analysis}

The limma package $[93,94]$ available from Bioconductor was used to conduct three analyses to statistically identify differentially expressed genes. In the first analysis, linear models were fit to each gene. These models used coefficients to denote each of the five treatments by sampling time combinations. The following coefficients were contrasted: Day 0 versus NR 5 dpa (NR5), Day 0 versus DL 5 dpa (DL5), Day 0 versus NR 14 dpa (NR14), Day 0 versus DL 14 dpa (DL14), NR5 versus NR14, and DL5 versus DL14. The other two analyses were equivalent to paired $t$ tests and compared NR5 versus DL5, and NR14 versus DL14. Multiple testing was corrected using an FDR cut-off of 0.05 and then a fold-change filter ( $\geq 1.5$-fold change) was implemented to derive final gene lists. All microarray data are available at [95]. The identity of differentially expressed salamander transcripts was inferred from presumptive human orthologs. Orthology was assumed for all salamander transcripts that exhibited significant sequence similarity to protein coding sequences from human RefSeq and nr databases (BLASTx, $e<1 \times 10^{-7}$ ). $K$ means gene clustering was performed using the Genesis software package [96]. Presumptive human-salamander orthologs were further annotated using GO terms and tools provided by the Database for Annotation, Visualization, and Integrated Discovery [97]. Significantly overrepresented GO terms (EASE score $p<0.01$ ) were identified for specific treatment/sampling time combinations. Certain GO terms were excluded from the results if similar information was represented by a similar GO term. The null expectation for GO term representation was obtained by assigning GO terms to 3271 EST contigs from Ambystoma ESTdb [95].

\section{4 cDNA Sequence Analysis}

The same total RNA samples that were used in the microarray analysis were used to produce cDNA templates for 454 pyrosequencing. cDNA libraries were generated for Day 0, NR5, NR14, DL5, and DL14 RNA samples using the Super SMART cDNA Synthesis protocol (Clontech, Mountain View, CA). Single-stranded cDNA template was amplified using the Advantage 2 PCR Kit (Clontech) and size selected according to manufacturer's instructions.
cDNAs were sequenced using the Genome Sequencer FLX System (Roche Applied Science, Indianapolis, IN). SeqClean was used for vector/poor quality trimming, bacterial contaminant screening, and identification of $A$. mexicanum mitochondrial DNA and rDNA sequences [98]. Retained sequences were pre-clustered using PaCE and then assembled using CAP3 with a 90\% sequence similarity threshold $[99,100]$. Contigs (including singletons) were searched using BLAST algorithms against the Ambystoma ESTdb, human and nr RefSeq databases, and Xenopus laevis and X. tropicalis Unigene sets. Annotated queries that returned a significant BLAST hit were assigned the gene identifier of the best-matching subject sequence. All of these new 454 sequence reads have been submitted to the Short Read Archive (SRA) at the National Center for Biotechnology Information (NCBI), accession SRA004195.2. 454 Sequences were assembled with previous EST data and are available at Sal-Site [95].

The number of times each 454 DNA sequence read matched a unique EST contig from the Ambystoma ESTdb was recorded, and these count data were used to estimate mRNA abundances for presumptive axolotl genes. The following method was used to identify differentially expressed genes among 10,275 contigs that were sampled $\geq 5$ times across all five cDNA libraries. First, 5000 random draws were taken from a multinomial distribution to derive expected count data for each gene $(k=5 \mathrm{cDNA}$ libraries, $n=$ the sum of counts across all libraries for a given gene, and $p_{1}, p_{2}, p_{3}, p_{4}$ and $p_{5}=$ expected proportion of counts per library given unequal sampling among cDNA libraries). Then, $\chi^{2}$ statistics were calculated, on a gene-by-gene basis, for each of these random draws. P-values for each gene were estimated by calculating the proportion of randomized $\chi^{2}$ statistics that were $\geq$ to the $\chi^{2}$ statistic associated with the observed data. Contigs with $P$ values $\leq 0.001$ were considered differentially expressed. Upon examination of this dataset, it was noticed that 589 of the significant EST contigs were uniquely derived from different CDNA libraries and these tended to form small (< $250 \mathrm{bp}$ ) contigs that did not match previous sequences in the Ambystoma ESTdb. These sequences were considered cloning/sequencing artifacts and removed from the dataset. This yielded a final dataset of 1150 significant genes. $\mathrm{GO}$ analyses were performed as described above with the exception that human default GO term frequencies were used to establish null expectations (EASE score $p<0.02$ ).

\section{Authors' contributions}

JRM and LGE performed surgeries, tissue collections, and RNA isolations. SP gave bioinformatic support and assembly of 454 sequences. RBP performed statistical analysis of microarray and 454 data. JRM and JAW performed histology, immunohistochemistry, and real-time PCR. SRV performed 454 sequencing template preparations. SRV and 
JRM drafted the manuscript. CKB, WZ, GMP, IMV, TH, SVB, DMG TTH, SRV, and JRM participated in the design of the study and helped draft the manuscript. All authors read and approved the final manuscript.

\section{Additional material}

\section{Additional file 1}

371 unique probe sets upregulated from baseline (D0). The data show all the significant genes identified as upregulated from baseline. The blank cells represent insignificant results at particular time points. Gene functions were hand-annotated using gene ontology terminology, NCBI Entrez Gene descriptions, and Pubmed searches.

Click here for file

[http://www.biomedcentral.com/content/supplementary/17417007-7-1-S1.xls]

\section{Additional file 2}

336 unique probe sets that were downregulated from baseline (D0). The data show all the significant genes identified as downregulated from baseline. The blank cells represent insignificant results at particular time points. Gene functions were hand-annotated using GO terminology, NCBI Entrez Gene descriptions, and Pubmed searches.

Click here for file

[http://www.biomedcentral.com/content/supplementary/17417007-7-1-S2.xls]

\section{Additional file 3}

33 unique probe sets that were significantly different between NR5 and DL5. The data shows the genes that were identified as differentially expressed between NR5 and DL5 limbs. Blank cells represent insignificant results at particular time points. Gene functions were hand-annotated using GO terminology, NCBI Entrez Gene descriptions, and Pubmed searches.

Click here for file

[http://www.biomedcentral.com/content/supplementary/17417007-7-1-S3.xls]

\section{Additional file 4}

282 unique probe sets that were significantly different between NR14 and DL14. The data shows the genes that were identified as differentially expressed between NR14 and DL14 limbs. Blank cells represent insignificant results at particular time points. Gene functions were hand-annotated using GO terminology, NCBI Entrez Gene descriptions, and Pubmed searches.

Click here for file

[http://www.biomedcentral.com/content/supplementary/17417007-7-1-S4.xls]

\section{Additional file 5}

1150 contigs that differed significantly in abundance between cDNA libraries according to 454 sequencing. The data show the normalized counts for genes that were identified as differentially expressed between any of the five libraries. Genes with significant human hits were handannotated using GO terminology, NCBI Entrez Gene descriptions, and Pubmed searches.

Click here for file

[http://www.biomedcentral.com/content/supplementary/17417007-7-1-S5.xls]

\section{Additional file 6}

104 genes that were represented on both platforms and found to be differentially expressed according to both microarry and 454 sequencing. The data show the normalized counts for genes identified using 454 sequencing and fold changes for genes identified using microarray analysis. Gene functions were hand-annotated using GO terminology, NCBI Entrez Gene descriptions, and Pubmed searches.

Click here for file

[http://www.biomedcentral.com/content/supplementary/17417007-7-1-S6.xls]

\section{Additional file 7}

Lowly-expressed develeopmental genes from D14 limbs. Important developmental genes that yielded weak, but significant hybridization signals between NR14 and DL14 limbs.

Click here for file

[http://www.biomedcentral.com/content/supplementary/1741-

7007-7-1-S7.xls

\section{Acknowledgements}

This project was supported by grants R24-RR016344 and P20-RR01674 I from the National Center for Research Resources (NCRR), a component of the National Institutes of Health (NIH). Its contents are solely the responsibility of the authors and do not necessarily represent the official views of NCRR or NIH. The project was also supported by a Roche genome sequencing award, funding from the Kentucky Spinal Cord and Brain Injury Research Trust, the California Institute for Regenerative Medicine, and the Kentucky Bioinformatics Research Infrastructure Network. The Spinal Cord and Brain Injury Research Center and the NSF supported Ambystoma Genetic Stock Center (DBI-0443496) provided resources and facilities. We thank Ananth Kalyanaraman for running PaCE clustering at Washington State University. Arnold Stromberg and Phil Crowly provided statistical advice.

\section{References}

I. Dinsmore CE: A history of regeneration research: Milestones in the evolution of science Cambridge: Cambridge University Press; 1991.

2. Carlson MR, Komine Y, Bryant SV, Gardiner DM: Expression of Hoxb 13 and Hoxcl 0 in developing and regenerating Axolotl limbs and tails. Dev Biol 200I, 229:396-406.

3. Christensen RN, Weinstein M, Tassava RA: Fibroblast growth factors in regenerating limbs of Ambystoma: cloning and semiquantitative RT-PCR expression studies. J Exp Zool 200I, 290:529-540.

4. Christensen RN, Weinstein M, Tassava RA: Expression of fibroblast growth factors 4,8 , and 10 in limbs, flanks, and blastemas of Ambystoma. Dev Dyn 2002, 223:193-203.

5. Endo T, Bryant SV, Gardiner DM: A stepwise model system for limb regeneration. Dev Biol 2004, 270: I35-I45.

6. Kumar A, Velloso CP, Imokawa Y, Brockes JP: The regenerative plasticity of isolated urodele myofibers and its dependence on MSXI. PLoS Biol 2004, 2:E2 I8.

7. Mercader N, Tanaka EM, Torres M: Proximodistal identity during vertebrate limb regeneration is regulated by Meis homeodomain proteins. Development 2005, |32:4|3|-4|42.

8. Schnapp E, Kragl M, Rubin L, Tanaka EM: Hedgehog signaling controls dorsoventral patterning, blastema cell proliferation and cartilage induction during axolotl tail regeneration. Development 2005, 132:3243-3253.

9. Levesque M, Gatien S, Finnson K, Desmeules S, Villiard E, Pilote M, Philip A, Roy S: Transforming growth factor: beta signaling is essential for limb regeneration in axolotls. PLOS ONE 2007, 2:el 227.

10. Satoh A, Gardiner DM, Bryant SV, Endo T: Nerve-induced ectopic limb blastemas in the axolotl are equivalent to amputationinduced blastemas. Dev Biol 2007, 3 | 2:23 |-244. 
II. Satoh A, Graham GM, Bryant SV, Gardiner DM: Neurotrophic regulation of epidermal dedifferentiation during wound healing and limb regeneration in the axolotl (Ambystoma mexicanum). Dev Biol 2008, 3 19:32I-335.

12. Theodosiou M, Monaghan JR, Spencer ML, Voss SR, Noonan DJ: Isolation and characterization of axolotI NPDC-I and its effects on retinoic acid receptor signaling. Comp Biochem Physiol B Biochem Mol Biol 2007, 147:260-270.

13. Villiard E, Brinkmann H, Moiseeva O, Mallette FA, Ferbeyre G, Roy S: Urodele $\mathrm{p} 53$ tolerates amino acid changes found in $\mathrm{p} 53$ variants linked to human cancer. BMC Evol Biol 2007, 7:180.

14. Ghosh S, Roy S, Seguin C, Bryant SV, Gardiner DM: Analysis of the expression and function of Wnt-5a and Wnt-5b in developing and regenerating axolotl (Ambystoma mexicanum) limbs. Dev Growth Differ 2008, 50:289-297.

15. Todd TJ: On the process of reproduction of the members of the aquatic salamander. J Sci Lit Arts 1823, 16:84-96.

16. Singer $M$ : The influence of the nerve in regeneration of the amphibian extremity. Q Rev Biol 1952, 27:169-200.

17. Singer $M:$ On the nature of the neurotrophic phenomenon in urodele limb regeneration. Am Zool |978, | 8:829-84 I.

18. Bryant SV, Endo T, Gardiner DM: Vertebrate limb regeneration and the origin of limb stem cells. Int J Dev Biol 2002, 46:887-896.

19. Mescher AL: The cellular basis of limb regeneration in urodeles. Int J Dev Biol 1996, 40:785-795

20. Bryant SV, Fyfe D, Singer M: The effects of denervation on the ultrastructure of young limb regenerates in the newt, Triturus. Dev Biol 197I, 24:577-595.

21. Mescher AL, Tassava RA: Denervation effects on DNA replication and mitosis during the initiation of limb regeneration in adult newts. Dev Biol 1975, 44:187-197.

22. Geraudie J, Singer M: Scanning electron microscopy of the normal and denervated limb regenerate in the newt, Notophthalmus, including observations on embryonic amphibia limb-bud mesenchyme and blastemas of fish-fin regenerates. Am J Anat 198I, 162:73-87.

23. Olsen CL, Barger PM, Tassava RA: Rescue of blocked cells by reinnervation in denervated forelimb stumps of larval Ambystoma. Dev Biol 1984, 106:399-405.

24. Olsen CL, Tassava RA: Cell cycle and histological effects of reinnervation in denervated forelimb stumps of larval Ambystoma. J Exp Zool 1984, 229:247-258.

25. Barger PM, Tassava RA: Kinetics of cell cycle entry in innervated and denervated forelimb stumps of larval Ambystoma. J Exp Zool 1985, 233:15।-154

26. Ferretti $\mathrm{P}$, Brockes JP: Cell origin and identity in limb regeneration and development. Glia I99|, 4:214-224.

27. Irvin BC, Tassava RA: Effects of peripheral nerve implants on the regeneration of partially and fully innervated urodele forelimbs. Wound Repair Regen 1998, 6:382-387.

28. Tassava RA, Olsen-Winner CL: Responses to amputation of denervated Ambystoma limbs containing aneurogenic limb grafts. I Exp Zoolog A Comp Exp Biol 2003, 297:64-79.

29. Brockes JP, Kintner CR: Glial growth factor and nerve-dependent proliferation in the regeneration blastema of Urodele amphibians. Cell 1986, 45:301-306.

30. Smith MJ, Globus M, Vethamany-Globus S: Nerve extracts and substance $P$ activate the phosphatidylinositol signaling pathway and mitogenesis in newt forelimb regenerates. Dev Bio 1995, |67:239-251.

31. Mullen LM, Bryant SV, Torok MA, Blumberg B, Gardiner DM: Nerve dependency of regeneration: the role of Distal-less and FGF signaling in amphibian limb regeneration. Development 1996, 122:3487-3497.

32. Mescher AL, Connell E, Hsu C, Patel C, Overton B: Transferrin is necessary and sufficient for the neural effect on growth in amphibian limb regeneration blastemas. Dev Growth Differ 1997, 39:677-684

33. Wang L, Marchionni MA, Tassava RA: Cloning and neuronal expression of a type III newt neuregulin and rescue of denervated, nerve-dependent newt limb blastemas by rhGGF2. J Neurobiol 2000, 43: 150-158.

34. Kumar A, Godwin JW, Gates PB, Garza-Garcia AA, Brockes JP. Molecular basis for the nerve dependence of limb regeneration in an adult vertebrate. Science 2007, 318:772-777.
35. Page RB, Monaghan JR, Samuels AK, Smith J], Beachy CK, Voss SR: Microarray analysis identifies keratin loci as sensitive biomarkers for thyroid hormone disruption in the salamander Ambystoma mexicanum. Comp Biochem Physiol C Toxicol Pharmacol 2007, I45:15-27.

36. Page RB, Voss SR, Samuels AK, Smith J], Putta S, Beachy CK: Effect of thyroid hormone concentration on the transcriptional response underlying induced metamorphosis in the Mexican axolotl (Ambystoma). BMC Genomics 2008, 9:78.

37. Monaghan JR, Walker JA, Page RB, Putta S, Beachy CK, Voss SR: Early gene expression during natural spinal cord regeneration in the salamander Ambystoma mexicanum. I Neurochem 2007, 101:27-40.

38. Stewart JD, Storfer A, Page RB, Beachy CK, Voss SR: Transcriptional response of Mexican axolotls to Ambystoma tigrinum virus (ATV) infection. BMC Genomics 2008, 9:493.

39. Deck JD: The histological effects of partial denervation and amputation in larval salamander forelimbs. I Exp Zool |96|, 148:69-79.

40. Carlone RI, Mescher AL: Trophic factors from nerves. In Regulation of Vertebrate Limb Regeneration Edited by: Sicard RE. New York: Oxford University Press; 1985:93-105.

4I. Tank PW, Carlson BM, Connelly TG: A staging system for forelimb regeneration in the axolotl, Ambystoma mexicanum. J Morphol 1976, I50: I 17-I28.

42. Putta S, Smith J], Walker JA, Rondet M, Weisrock DW, Monaghan J, Samuels AK, Kump K, King DC, Maness NJ, Habermann B, Tanake E, Bryant SV, Gardiner DM, Parichy DM, Voss SR: From biomedicine to natural history research: EST resources for ambystomatid salamanders. BMC Genomics 2004, 5:54

43. Schotte OE, Butler EG: Morphological effects of denervation and amputation of limbs in Urodele larvae. J Exp Zool I94I, 87:279-322

44. Thorton CS: Histological modifications in denervated injured forelimbs of amblystoma larvae. J Exp Zool 1953, I 22: I 19-1 40.

45. Tank PW, Holder N: The distribution of cells in the upper forelimb of the axolotl, Ambystoma mexicanum. J Exp Zool 1979 , 209:435-442.

46. Hay ED: Electron microscopic observations of muscle dedifferentiation in regeneration of Amblystoma limbs. Dev Biol 1959, I:555-585.

47. Petrosky NS, Tassava RA, Olsen CL: Cellular events in denervated limb stumps of Ambystoma larvae during re-innervation and subsequent regeneration. Experientia 1980, 36:60I-603.

48. Lo DC, Allen F, Brockes JP: Reversal of muscle differentiation during urodele limb regeneration. Proc Natl Acad Sci USA 1993, 90:7230-7234.

49. Kumar A, Velloso CP, Imokawa Y, Brockes JP: Plasticity of retrovirus-labelled myotubes in the newt limb regeneration blastema. Dev Biol 2000, 2 I 8: 125-136.

50. Echeverri K, Clarke JD, Tanaka EM: In vivo imaging indicates muscle fiber dedifferentiation is a major contributor to the regenerating tail blastema. Dev Biol 200I, 236: I5I-I64.

5I. Goetsch SC, Hawke TJ, Gallardo TD, Richardson JA, Garry DJ: Transcriptional profiling and regulation of the extracellular matrix during muscle regeneration. Physiol Genomics 2003, |4:26|-27|.

52. Morrison II, Loof S, He P, Simon A: Salamander limb regeneration involves the activation of a multipotent skeletal muscle satellite cell population. J Cell Biol 2006, 172:433-440.

53. Cameron JA, Hilgers AR, Hinterberger TJ: Evidence that reserve cells are a source of regenerated adult newt muscle in vitro. Nature 1986, 321:607-610

54. Iwasaki K, Hayashi K, Fujioka T, Sobue K: Rho/Rho-associated Kinase Signal Regulates Myogenic Differentiation via Myocardin-related Transcription Factor-A/Smad-dependent Transcription of the Id3 Gene. J Biol Chem 2008, 283:2|230-2|24|

55. Buratti E, Baralle FE: Multiple roles of TDP-43 in gene expression, splicing regulation, and human disease. Front Biosci 2008 , 1 3:867-878

56. Winkler GS, Mulder KW, Bardwell VJ, Kalkhoven E, Timmers HT: Human Ccr4-Not complex is a ligand-dependent repressor of nuclear receptor-mediated transcription. EMBO | 2006, 25:3089-3099. 
57. Schnapp E, Tanaka EM: Quantitative evaluation of morpholinomediated protein knockdown of GFP, MSXI, and PAX7 during tail regeneration in Ambystoma mexicanum. Dev Dyn 2005 232:162-170.

58. Costa S, Shaw P: 'Open minded' cells: how cells can change fate. Trends Cell Biol 2007, I7:I0I-I06.

59. Maherali N, Sridharan R, Xie W, Utikal J, Eminli S, Arnold K, Stadtfeld M, Yachechko R, Tchieu J, Jaenisch R, Plath K, Hochedlinger K: Directly reprogrammed fibroblasts show global epigenetic remodeling and widespread tissue contribution. Cell Stem Cell 2007, I:55-70.

60. Yakushiji N, Suzuki M, Satoh A, Sagai T, Shiroishi T, Kobayashi H, Sasaki $\mathrm{H}$, Ide $\mathrm{H}$, Tamura K: Correlation between Shh expression and DNA methylation status of the limb-specific Shh enhancer region during limb regeneration in amphibians. Dev Biol 2007, 3 I 2: 17। - I82

61. Palacios D, Puri PL: The epigenetic network regulating muscle development and regeneration. J Cell Physiol 2006, 207: I-I I.

62. Sharif J, Muto M, Takebayashi S, Suetake I, Iwamatsu A, Endo TA, Shinga J, Mizutani-Koseki Y, Toyoda T, Okamura K, Tajima S, Mitsuya K, Okano M, Koseki H: The SRA protein Np95 mediates epigenetic inheritance by recruiting Dnmtl to methylated DNA Nature 2007, 450:908-912.

63. Guastafierro T, Cecchinelli B, Zampieri M, Reale A, Riggio G, Sthandier O, Zupi G, Calabrese L, Caiafa P: CTCF activates PARP-I affecting DNA methylation machinery. J Biol Chem 2008, 283:21873-21880

64. Dorner D, Gotzmann J, Foisner R: Nucleoplasmic lamins and their interaction partners, LAP2alpha, Rb, and BAF, in transcriptional regulation. FEBS J 2007, 274: I362-I373.

65. Shrivastav M, De Haro LP, Nickoloff JA: Regulation of DNA double-strand break repair pathway choice. Cell Res 2008, 18:134-147.

66. Thomas JO: HMGI and 2: architectural DNA-binding proteins. Biochem Soc Trans 200I, 29:395-40I.

67. Saharia A, Guittat L, Crocker S, Lim A, Steffen M, Kulkarni S, Stewart SA: Flap endonuclease I contributes to telomere stability. Curr Biol 2008, 18:496-500.

68. Yang $\mathrm{H}$, Ou CC, Feldman RI, Nicosia SV, Kruk PA, Cheng JQ: Aurora-A kinase regulates telomerase activity through $\mathrm{C}$ Myc in human ovarian and breast epithelial cells. Cancer Res 2004, 64:463-467.

69. Monaco L, Kolthur-Seetharam U, Loury R, Murcia JM, de Murcia G, Sassone-Corsi P: Inhibition of Aurora-B kinase activity by poly(ADP-ribosyl)ation in response to DNA damage. Proc Natl Acad Sci USA 2005, 102: I 4244-I 4248.

70. Mateyak MK, Zakian VA: Human PIF helicase is cell cycle regulated and associates with telomerase. Cell Cycle 2006, 5:2796-2804.

7I. Kano H, Kurahashi H, Toda T: Genetically regulated epigenetic transcriptional activation of retrotransposon insertion confers mouse dactylaplasia phenotype. Proc Natl Acad Sci USA 2007, 104: 19034-19039.

72. Cropley JE, Martin DI: Controlling elements are wild cards in the epigenomic deck. Proc Natl Acad Sci USA 2007 , 104:18879-18880

73. da Silva SM, Gates PB, Brockes JP: The newt ortholog of CD59 is implicated in proximodistal identity during amphibian limb regeneration. Dev Cell 2002, 3:547-555.

74. Globus M, Smith MJ, Vethamany-Globus S: Evidence supporting a mitogenic role for substance $P$ in amphibian limb regeneration. Involvement of the inositol phospholipid signaling pathway. Ann N Y Acad Sci 1991, 632:396-399.

75. Suzuki M, Satoh A, Ide H, Tamura K: Nerve-dependent and -independent events in blastema formation during Xenopus froglet limb regeneration. Dev Biol 2005, 286:36 I-375.

76. Han MJ, An JY, Kim WS: Expression patterns of Fgf-8 during development and limb regeneration of the axolotl. Dev Dyn 200I, 220:40-48.

77. Tassava RA, Bennett LL, Zitnik GD: DNA synthesis without mitosis in amputated denervated forelimbs of larval axolotls. J Exp Zool 1974, 190: I I I-1 I6.

78. Maden M: Neurotrophic control of the cell cycle during amphibian limb regeneration. J Embryol Exp Morphol 1978, 48:169-175.
79. Loyd RM, Connelly TG: Microdensitometric analysis of denervation effects on newt limb blastema cells. Experientia 198I, 37:967-969.

80. de Koning T], Snell K, Duran M, Berger R, Poll-The BT, Surtees R: Lserine in disease and development. Biochem J 2003, 37I:653-66I.

8I. Martens JW, Nimmrich I, Koenig T, Look MP, Harbeck N, Model F Kluth A, Bolt-de Vries J, Sieuwerts AM, Portengen H, Meijer-Van Gelder ME, Piepenbrock C, Olek A, Höfler H, Kiechle M, Klijn JG, Schmitt M, Maier S, Foekens JA: Association of DNA methylation of phosphoserine aminotransferase with response to endocrine therapy in patients with recurrent breast cancer. Cancer Res 2005, 65:4I0I-4III7.

82. Vié N, Copois V, Bascoul-Mollevi C, Denis V, Bec N, Robert B, Fraslon C, Conseiller E, Molina F, Larroque C, Martineau P, Del Rio M, Gongora : Overexpression of phosphoserine aminotransferase PSATI stimulates cell growth and increases chemoresistance of colon cancer cells. Mol Cancer 2008, 7:14.

83. Dresden $\mathrm{MH}$ : Denervation effects on newt limb regeneration: DNA, RNA, and protein synthesis. Dev Biol 1969, 19:3 I I-320.

84. Lebowitz P, Singer M: Neurotrophic control of protein synthesis in the regenerating limb of the newt, Triturus. Nature 1970, 225:824-827.

85. Singer M, Caston JD: Neurotrophic dependence of macromolecular synthesis in the early limb regenerate of the newt, Triturus. J Embryol Exp Morphol 1972, 28: I-I I.

86. Geraudie J, Singer M: Nerve-dependent macromolecular synthesis in the epidermis and blastema of the adult newt regenerate. J Exp Zool 1978, 203:455-460.

87. Emrich SJ, Barbazuk WB, Li L, Schnable PS: Gene discovery and annotation using LCM-454 transcriptome sequencing. Genome Res 2007, 17:69-73.

88. Toth AL, Varala K, Newman TC, Miguez FE, Hutchison SK, Willoughby DA, Simons JF, Egholm M, Hunt JH, Hudson ME, Robinson GE: Wasp gene expression supports an evolutionary link between maternal behavior and eusociality. Science 2007 , 3 I 8:44I-444.

89. Vera JC, Wheat CW, Fescemyer HW, Frilander MJ, Crawford DL, Hanski I, Marden JH: Rapid transcriptome characterization for a nonmodel organism using 454 pyrosequencing. Mol Ecol 2008, 17:1636-1647.

90. Bolstad B, Collin F, Brettshneider J, Simpson K, Cope L, Irizarry RA Speed TP: Bioinformatics and Computational Biology Solutions Using R and Bioconductor New York: Springer; 2005

91. Irizarry RA, Hobbs B, Collin F, Beazer-Barclay YD, Antonellis KJ, Scherf U, Speed TP: Exploration, normalization, and summaries of high density oligonucleotide array probe level data. Biostatistics 2003, 4:249-264.

92. Draghici S, Khatri P, Eklund AC, Szallasi Z: Reliability and reproducibility issues in DNA microarray measurements. Trends Genet 2006, 22:101-109.

93. Smyth GK: Linear models and empirical bayes methods for assessing differential expression in microarray experiments. Stat Appl Genet Mol Biol 2004, 3:Article3.

94. Smyth GK, Michaud J, Scott HS: Use of within-array replicate spots for assessing differential expression in microarray experiments. Bioinformatics 2005, 21:2067-2075.

95. Sal-Site, an integrated web portal for the Ambystoma research community [http://www.ambystoma.org]

96. Sturn A, Quackenbush J, Trajanoski Z: Genesis: cluster analysis of microarray data. Bioinformatics 2002, I8:207-208.

97. Dennis G Jr, Sherman BT, Hosack DA, Yang J, Gao W, Lane HC, Lempicki RA: DAVID: Database for Annotation, Visualization, and Integrated Discovery. Genome Biol 2003, 4:P3.

98. The Computational Biology and Functional Genomics Laboratory at the Dana Farber Institute [http://compbio.dfci.har vard.edu/tgi/software/]

99. Kalyanaraman A, Aluru S, Kothari S, Brendel V: Efficient clustering of large EST data sets on parallel computers. Nucleic Acids Res 2003, 31:2963-2974.

100. Huang $X$, Madan A: CAP3: A DNA sequence assembly program. Genome Res 1999, 9:868-877.

10I. Dahlquist KD, Salomonis N, Vranizan K, Lawlor SC, Conklin BR: GenMAPP, a new tool for viewing and analyzing microarray data on biological pathways. Nat Genet 2002, 3 I:19-20. 